Historic, archived document

Do not assume content reflects current scientific knowledge, policies, or practices. 



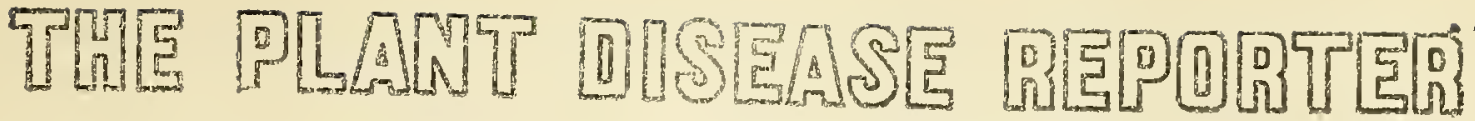

Isstued By

Division of Mycology and Disease. Survey

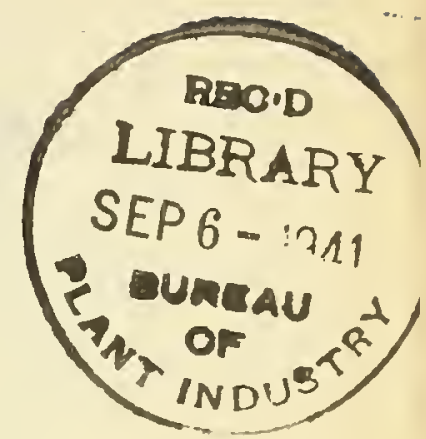

MUREAU OF MARE HNDUSTRY

UNTRE STATES DFFARTHERT OF" AGPGULTUPE

Supplement 127

Crop Losses From Plant Diseases in the

United States

1939

December $3 i, 1940$.

(Issued June 30, 1941)

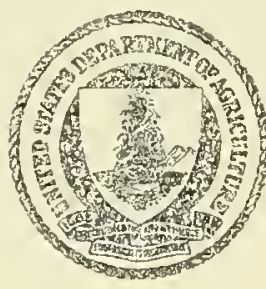

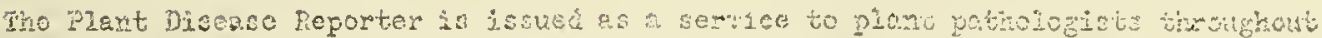
the Inited States. It containe reports, surraries, obsorrations, and cormente sulnitted

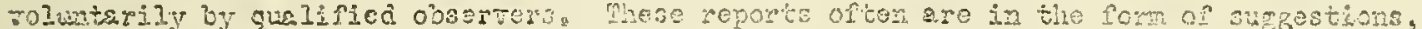
quavies, Lid opinions, frequenty purely tenteltire, offered for consideration or disous-

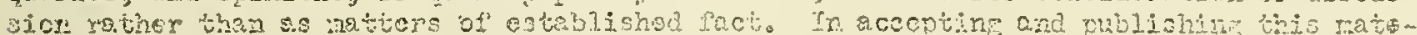

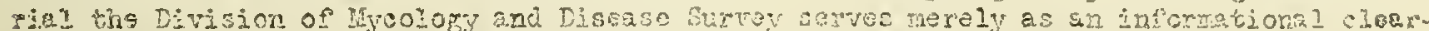

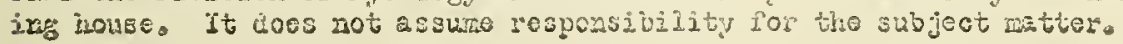





\title{
CRCP LOSSES FROM PLANT DISEASES IN THE UNITED STATES IN 1939
}

\author{
Compiled by
}

H. A. Edson and Jessie I. Wood

Plant Disease Reporter

December $31,19.40$

Supplement 127

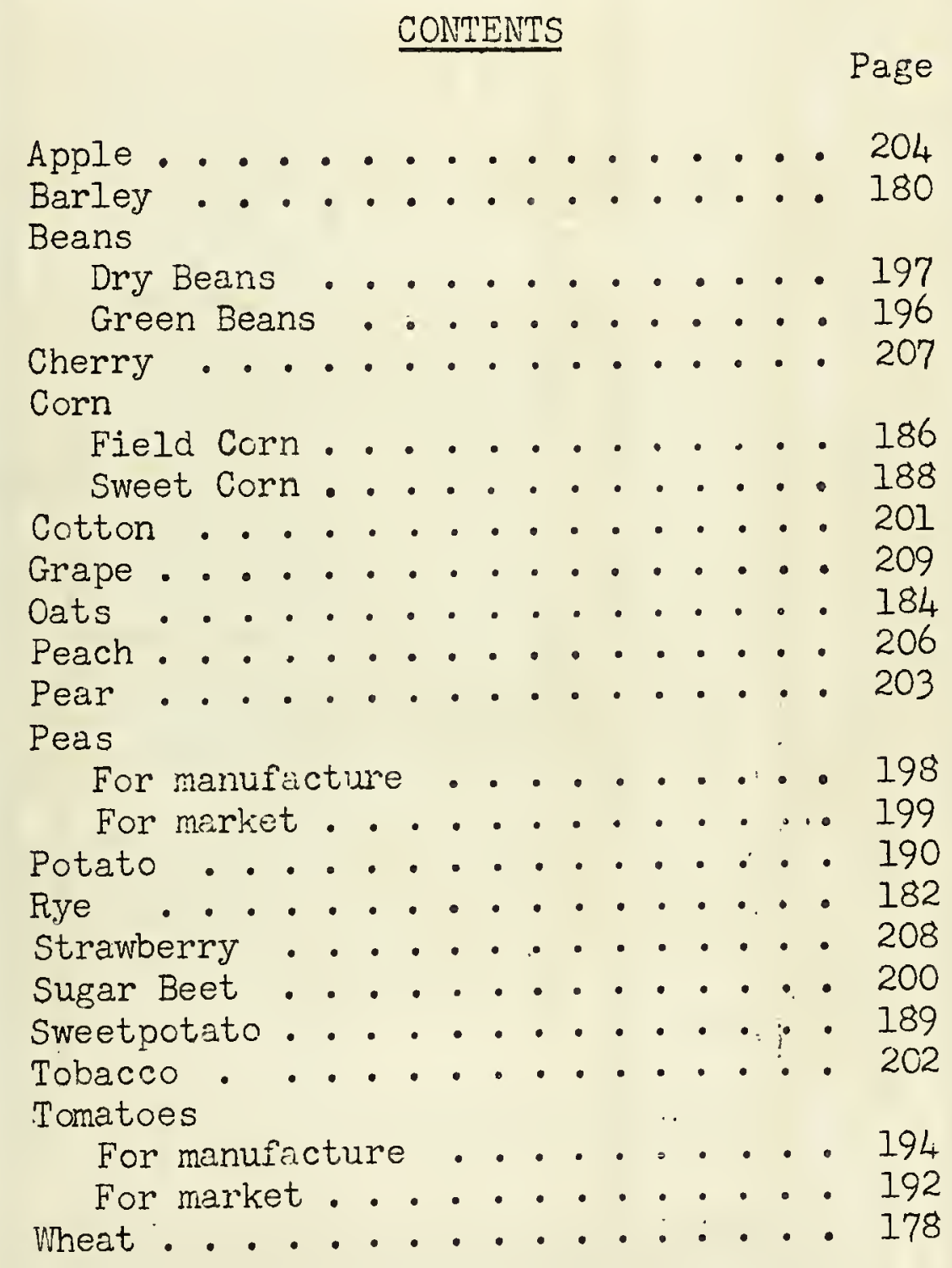




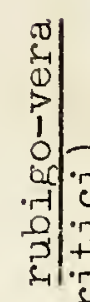

का

.

वर

o 品

落

$3+\infty$

\&

क्ष के

त)

. 81

का मे

勇 $=$

(0)

की की

हु

แ

○ م.

(1)

ठ․

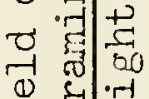

की क्वात्न

\&

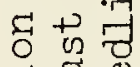

†?

ว

$\begin{array}{lll}0 & 0 & 0 \\ 0 & 0 & 0 \\ 0 & 0\end{array}$

व 20

क

:

है

|्| क्जि दो

-1
0
-1
0
0
0 


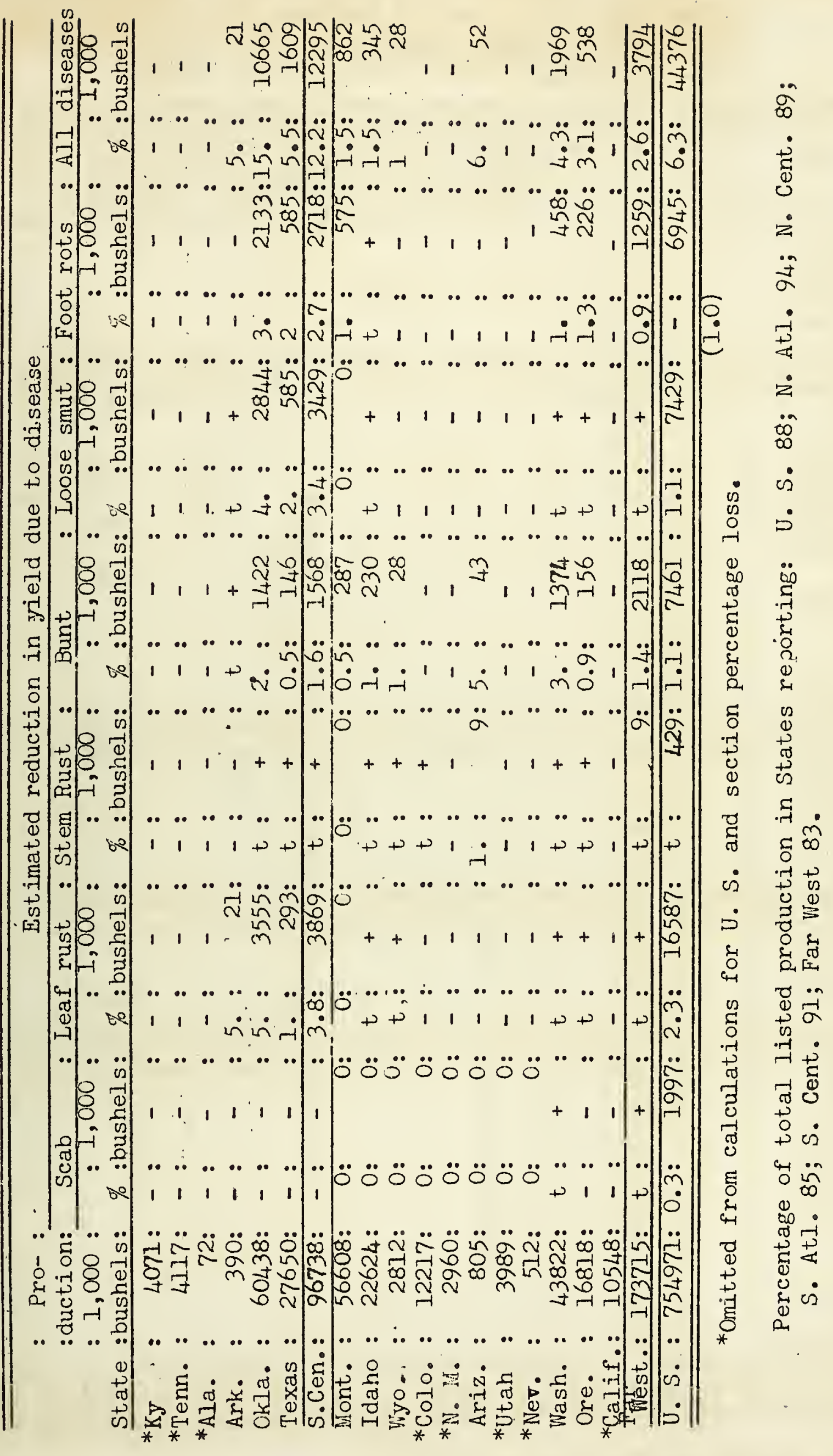


Table 2. Estimated reduction in yield from stripe (Helminthosporium gramineum), foot rots and seedling blights (Helminthosporium, Fusarium, Ophiobolus yraminis, and other fungi), loose smut (Ustilago nuda etc.). covered smut (U. hordei),

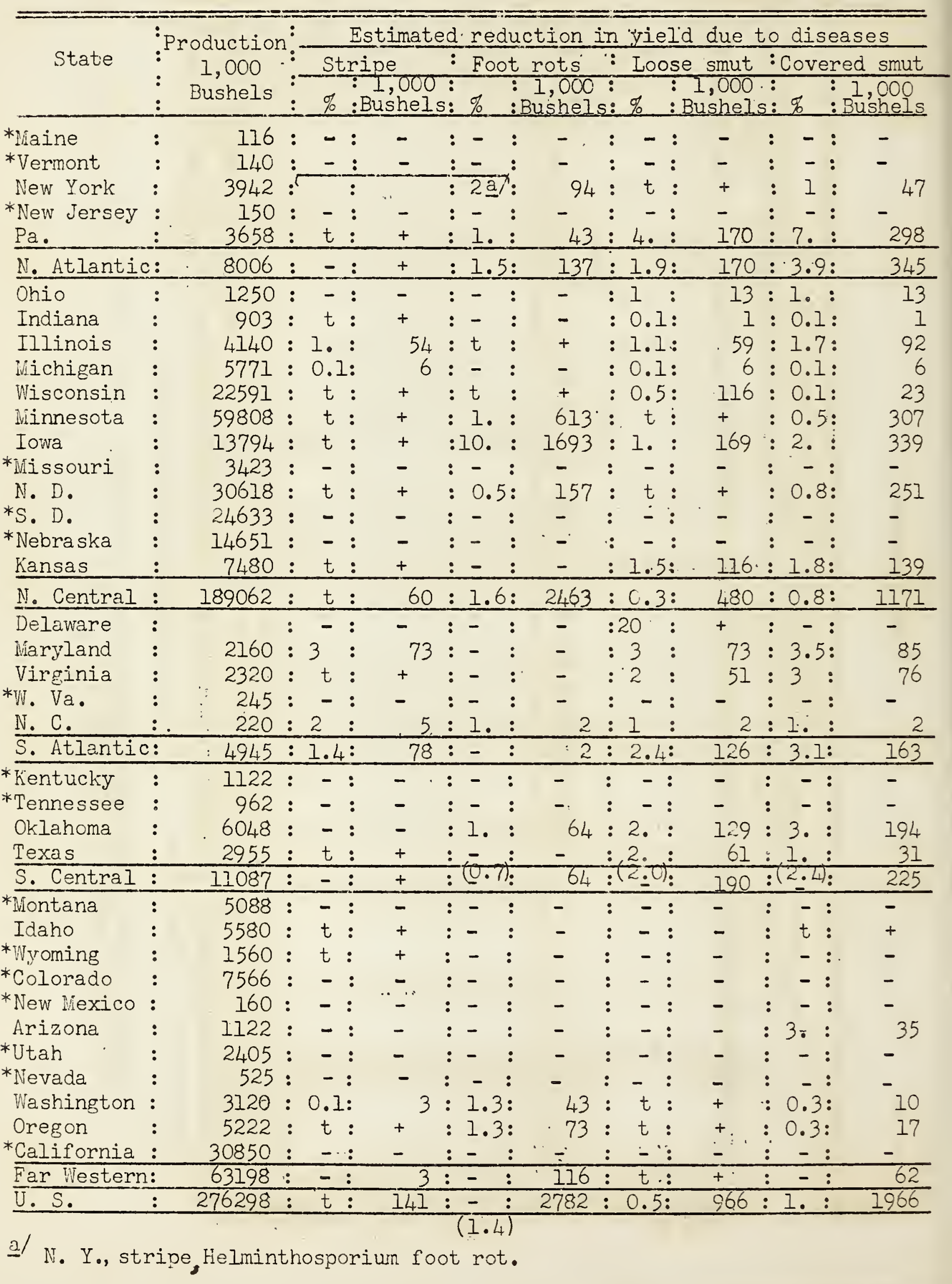


BAFIEI (Contirued)

Table 2 Scab (Gibberel]a zeae), powdery mildew (Ervsiphe graminis), leaf rusts (Puccinia anomala and P. rubigo-vera tritici), stem rust (P. gramiris), ind other disezses, 1339.

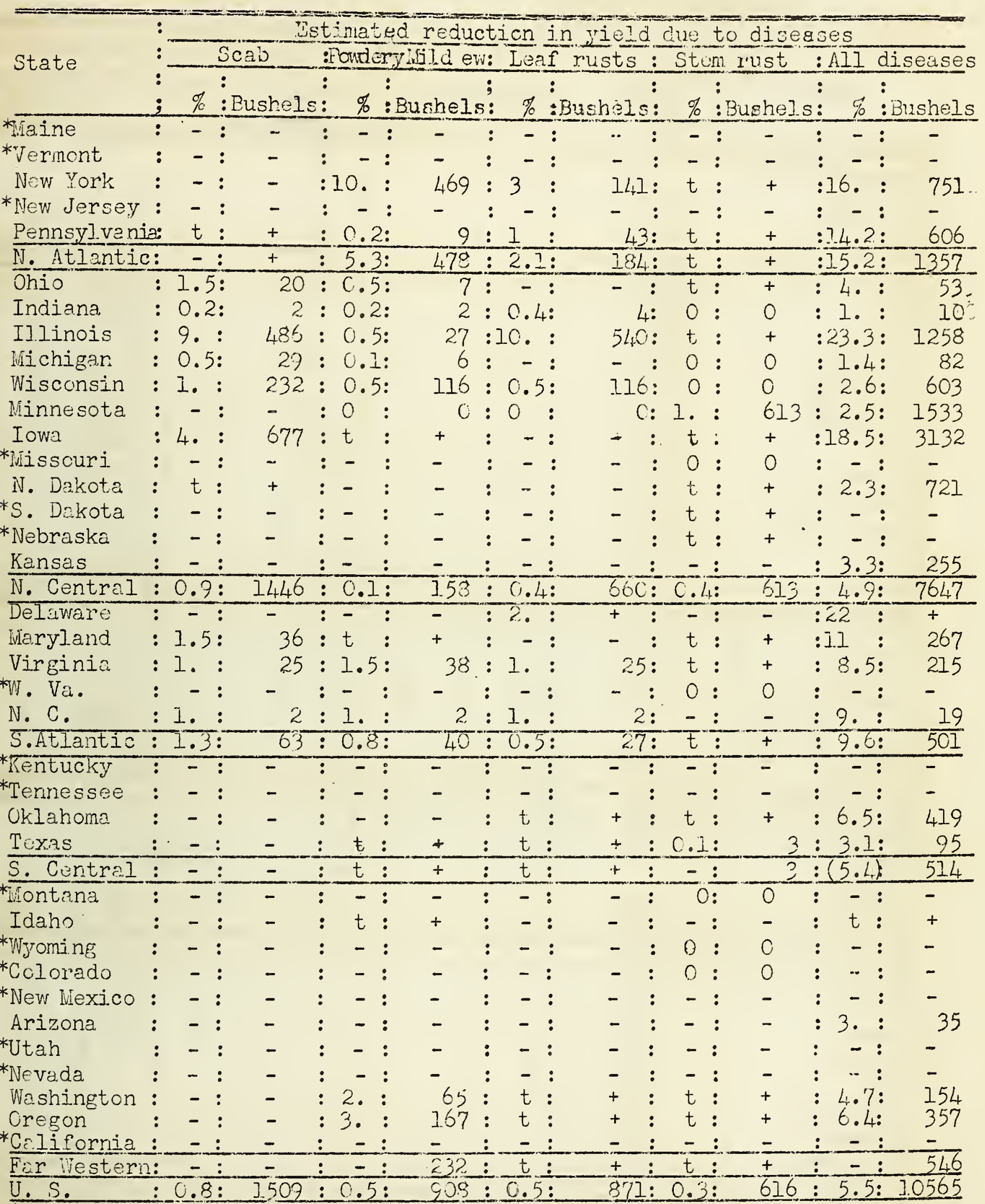

*omitted from calcuiations for United states and scetion percentage loss.

Percentage of total listed production in States reporting: U.S. 66, N.AtI.95, N. Cent. 77, S. Atl. 95, S. Cent. 81, Far jest 24. 
Table 3. Reduction in jield due to sinut (Urocystis occulta), ergot (Claviceps purpurea), leaf rust (Puccinia rubigo-vera secalis).

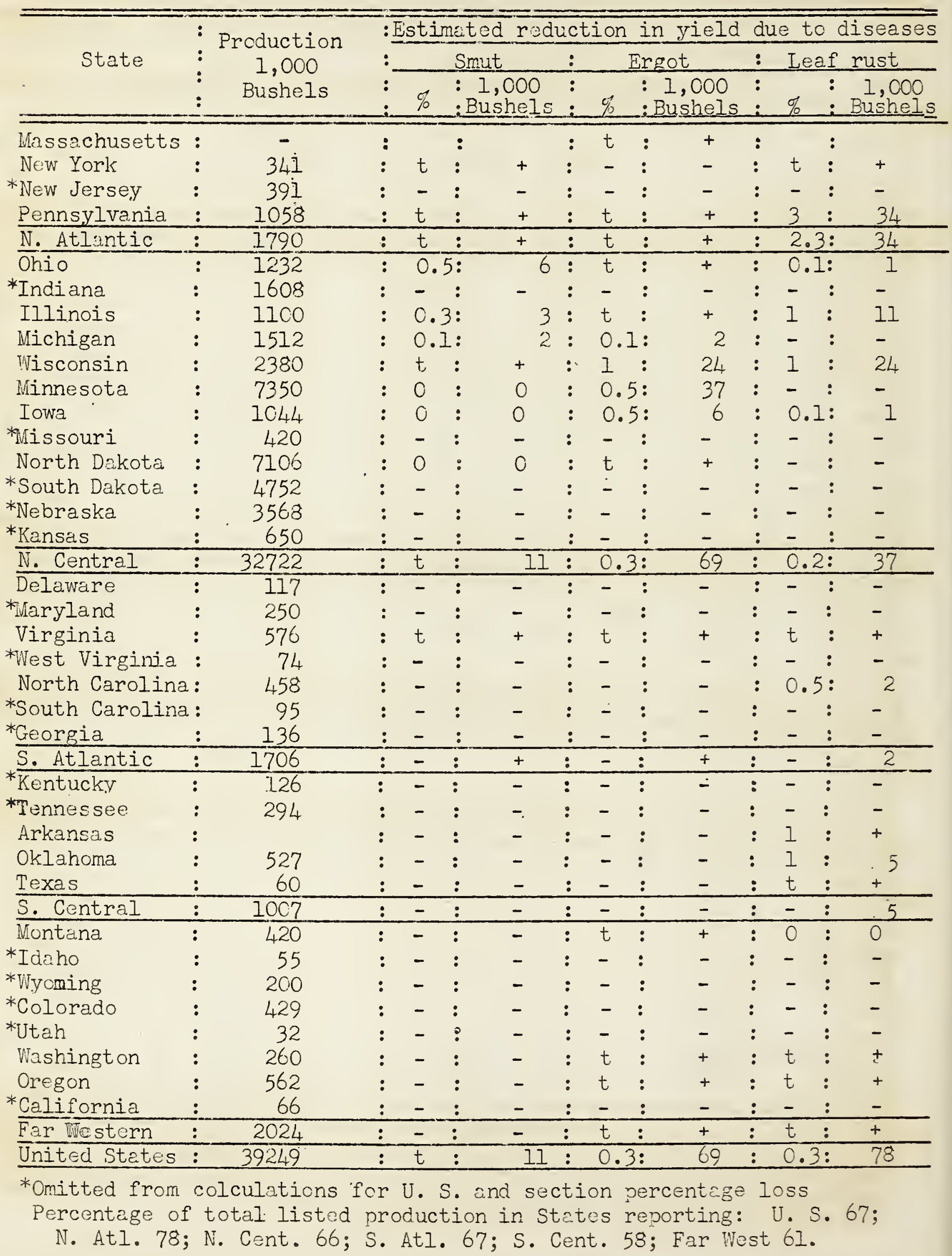


RYE(Continued)

Table . Stem rust (P. graminis), footrots and seedling blights (various organisms), anthracnose (Colletutrichum graminicola), and other diseases, 1939.

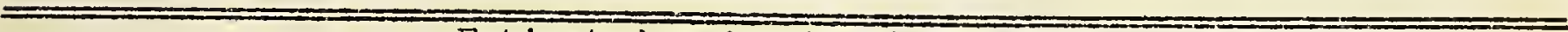
State $: \frac{\text { Estimated reduction in yield due to disease }}{\text { Stem Rust }: \text { Foot rots }: \text { Anthracnose }: \text { All diseases }}$ :\%:Bushels: \%:Bushels: \%:Bushels: \% :Bushels

Massachusetts : $1 .:$ :

New York

*New Jersey

Pennsylvania

N. Atlantic

Ohio

*Indiana

Illinois

Michigan

Wisconsin

Minnesota

Iowa

*Missouri

North Dakota

*South Dakota

* Nebraska

* Kansas

N. Central

Delaware

* Maryland

Virginia

* Nest Virginia:

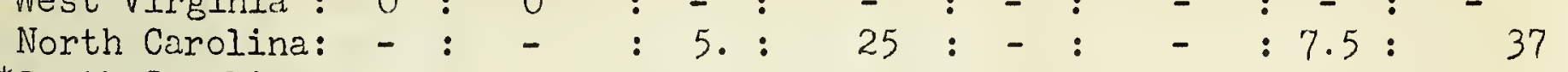

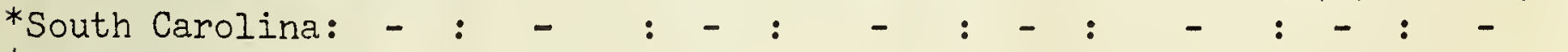

*Georgia

* Kentucky

*Tennessee

Arkansas

Oklahoma

Texas

S. Central

Montana

*Idaho

*Wyoming

*Colorado

*Utah

Washington

Oregon

*California

Far Western

United States

$:-:-$

$+$

$:-$

$\therefore \quad 25$

$\div-:-$

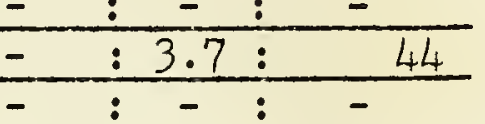

$55: 0.1: \quad 1: 5.7: 03$

$55: 0.1: \quad 1: 5.7: 03$ 
Table - Estimated reduction in vield due to loose smut (Ustilago avenae) ccvered smut ( $\underline{U}$. Levis), stem rust (Puccinia graminis).

$=0$ State Production due to diseases 1,000 Bushels

\begin{tabular}{|c|c|c|c|c|c|c|c|c|c|}
\hline mine & & & & & & & & & \\
\hline $\begin{array}{l}\text { aine } \\
\text { ew Hampshire }\end{array}$ & 4,598 & $: 0.3:$ & 14 & $=$ & $\vdots$ & $z$ & : & 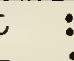 & + \\
\hline Vermont & 831 & & $:$ & $\begin{array}{l}- \\
-\end{array}$ & : & $\begin{array}{c}- \\
-\end{array}$ & & & $\bar{z}$ \\
\hline Massachusetts & 231 & $:$ & $10^{-}$ & $\mp$ & $:$ & $\mp$ & & & 2 \\
\hline *lihode Is. & : & : & & - & : & - & & & : \\
\hline * Connecticut & 13 & 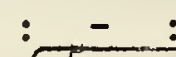 & - & - & : & - & & & \\
\hline New York & 25,806 & $\because$ & उ99? & 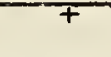 & & + & & & \\
\hline * New Jerse & $\frac{1}{2}, 260$ & $\vdots_{c}+a+1$ & - & - & : & - & & & - \\
\hline Pennsylvaria & $\frac{26,274}{6,16}$ & $\because 8$ & $2351=$ & \pm & $:$ & & & & \\
\hline I. Atlantic & 60,546 & $: 6.1:$ & 3774 & + & $:$ & + & & & 2 \\
\hline Ohic & $\begin{array}{l}33,150 \\
25,225 .\end{array}$ & $\vdots \frac{1}{1}$ & $\begin{array}{l}340 \\
260\end{array}$ & $\frac{1}{1}$ & $\vdots$ & $\begin{array}{l}340 \\
260 \\
-160\end{array}$ & & & +260 \\
\hline Indinoj.s & 93,540 & $: 2.3$ & 2880 & $\frac{1}{1}$. & & 1252 & & & \\
\hline Michigan & 42,712 & $: 0.2:$ & 86 & 0.1 & & 43 & & & + \\
\hline Wisconsin & $71,01.2$ & $: 4 .:$ & 3139 & 2 & & 1569 & & .5 & 392 \\
\hline Minnescta & 151, & $r$ & 3127 & + & & & & & + \\
\hline Lowa & 1.5 & $: 4.5$ & 9048 & 0.5 & & 1005 & & & : \\
\hline Missouri & 40,920 & $:-$ & - & - & & & & & + \\
\hline North Dakota & 35,297 & $: 0.5$ & 178 & 0.5 & & 178 & & & + \\
\hline & 27 & $:-$ & - & - & & - & & & + \\
\hline *Nebraska & 20,576 & $i=-$ & $\frac{-}{51}$ & - & & - & & & + \\
\hline
\end{tabular}

Kansas

21,173 : Loose smut Covered smut : Stem rust

N. Central

* Delaware

Naryland

Virêinia

West Virginia :

North Carolina:

* South Carolina:

Georgia

*Floride

S. Atlantic

* Kentucky

* Tennessee

* Alabarna

*Mississippi

Arkansas

*Louisiana

Oklahoma

Texas

S. Contral

Montana

Idaho

Wyoming

* Colorado

* New Mexico

Arizona

*Utah

* Nevada

Vashington

Oregon

$\frac{734,001}{87}$

$\div \frac{2.1}{2}$

195

1,128

1,600

1,460

5,692

$1.1,515$

8,945

: 2 .

(2)

$12 \div 0.6$

$: \quad+\quad 4647:$

int

$t:-652$

*Celifornia

30,552

$\frac{3 .}{5}$

$23:$

$-\quad: 0.1:$

61: ${ }^{1} t: t+$

1

Far Western

7,445

2,838

2,736

2,904

$\frac{52}{73}$

1,664

21,114

$\frac{28,750}{62,2,03}$

8,002

6,232

2,288

4,205

638
230

230
980

245

11,221

11,725

$20:-$

124

United States: 937.275

3,944

2.

$4:$

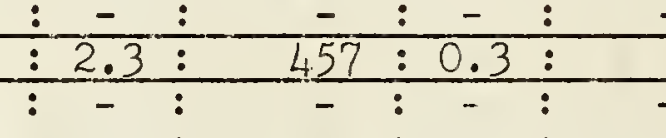

$61: 0.1: 18$

* Omitted from calculations for United States and section percentage loss.

Percentage of total listed production in States reporting: U.S., 85;

IN. Atl. 94; N. Cent. 86; S. Atl. 62; S. Cent. 85; Far Viest. 80. 
Table (Contirued). Crown rust (Puccinia coronata), blast (non-parasitic) and other diseases, 1939. - Estinatod reduction in yiold du to diseases

State : Crom must $:$ BI. $:$ ist Maine

* New Hampshire

*Vermont

Nassachusetts

*Rhode Island

*Connecticut

New York

* New Jersey.

: BusheIs.

: Busheds

$-$

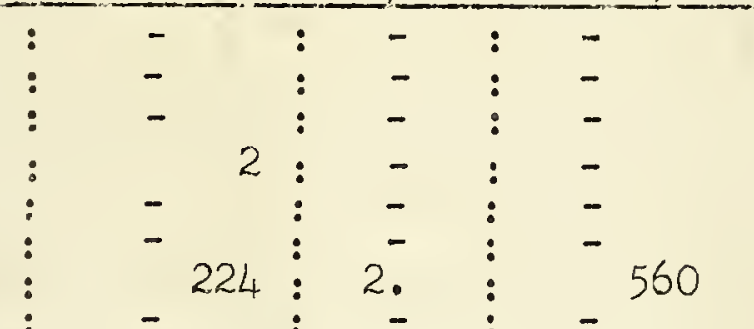

$\frac{8}{0.3:}$

Bustels

1.
-
0.8
-

- $29: 1.5$

- :

7.

7.:

$-:$

$7.8:$

$0.6:$

Pennsylvania

N. At]antic

Chio

Indiana

Illinois

Michigan

ivisconsin

lifinesota

Iova

* Missouri

North Dakota

* South Daliota

* Nebraska

Kansas

$\bar{N}$. Centril

* Delaware

Mary] and

Virginia

West Virginia

Nortin Carolina

* Soutin Carolina :

Georgia

$\frac{\text { * Florida }}{\text { S.At]antic }}$

*Ternes see

* Alizama

* Mississippi

Arkansas

* Lorrisiana.

Cklehoma

Texas

Montina

Idaho

Wyoning

*Colorado

* New Mexico

Arizona

*Utah

* Nevada

Washington

Oregon
*alifornia

0.1

$\frac{255}{170}$

$1.5: \quad 441$

$\div \frac{0.4}{0.5}$

$$
\text { : }
$$

t :

3.

$+\quad: t^{c}$

$\div-1001$

$:$

$\frac{10.6:}{8.6:}$

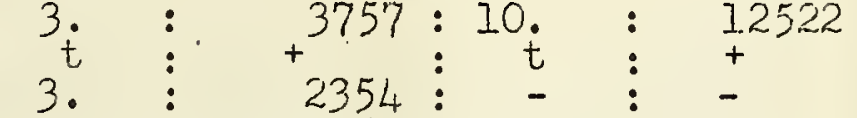

7

$\frac{1}{3} \cdot 5$

t : :

$\begin{array}{cccc}1563: & - & - \\ 7037 & 0.5 & \vdots & -1005 \\ - & - & 0\end{array}$

+
+2522
+
-
-

$2.5:$

3.:

$25 \cdot 3:$

9.: $:$

$23 . \vdots$

].

$-$

- :

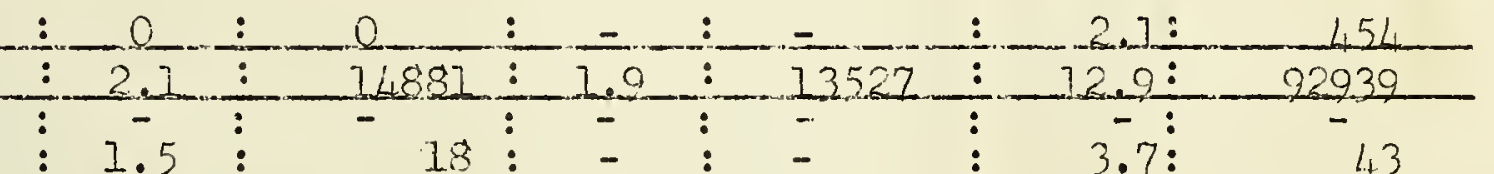

$1.5: 18 \div-180-3.7$

1.

$1^{t}$

1.: 60 :

1

$\begin{array}{r}-92: \\ -\quad-\quad 0 \\ \hline\end{array}$

$\div \frac{0.9}{-}$

Far Western

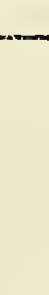

:

$\frac{187:}{-}$

$+$

$\therefore \quad$ C.2

:

$227:-$

$6 \cdot 5:$

3.:

$\frac{:}{\vdots}$

$46 \div-1:-$

$\vdots 0$

$: \quad 443$

$10 .-\frac{1}{\vdots}-941$

$-941$

- $\quad \vdots \quad-\quad \vdots \quad$

- :

- :

United States $\overline{-} \quad \vdots \quad \bar{z} \quad \vdots \quad$

$$
\text { (1) }
$$

123
$46:$

$0 . \overline{4}$

0.5
$5 \cdot 5:$

$-$

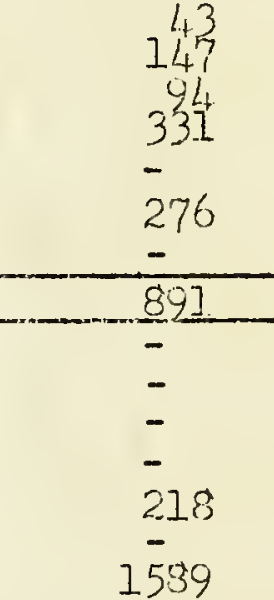

$7 . \vdots \quad 1539$

4.4:

- :

3129

1.412

$\begin{array}{r:r}t & \vdots \\ t & +\end{array}$

- :

- :

7.:

17

- :

$2.6:$

$4 \cdot 4:$

540
300 


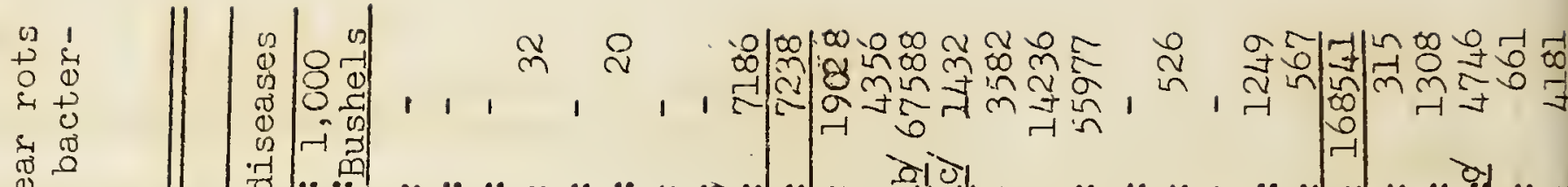
(1)

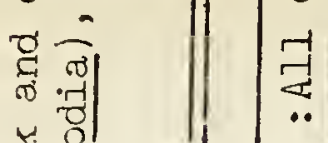
. 겅 ขค

$\frac{2}{0} \underset{c}{c}$

贾古

त्व

30

0

ऽ :

$0 \cdot \mathrm{c}$

$\cdot$.

के

os 0

+

至

(1.

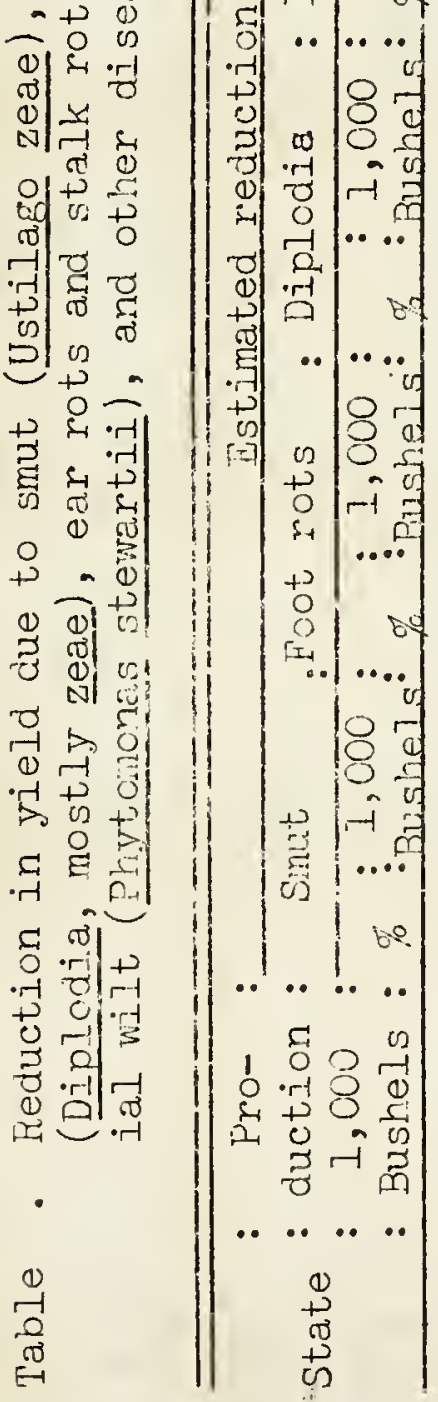

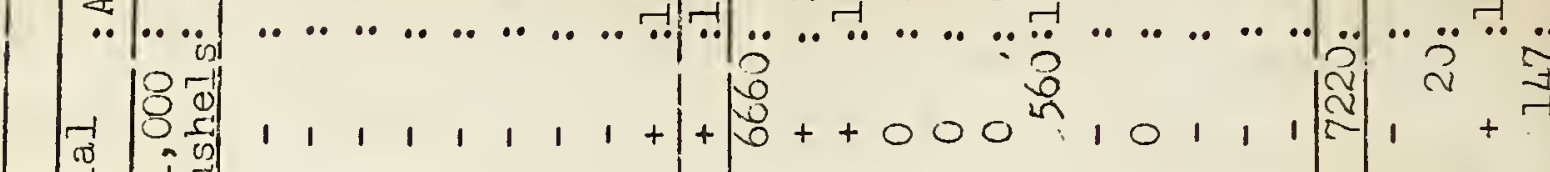

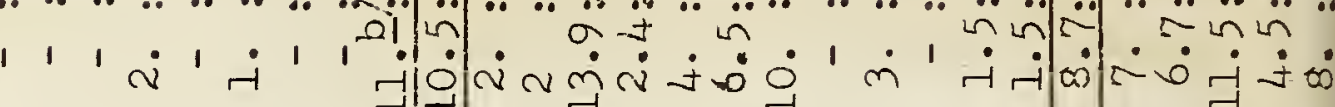

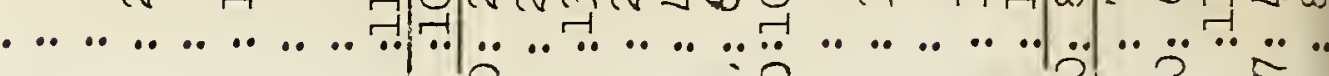

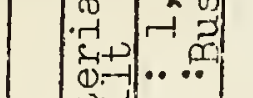

$$
\text { 1 }
$$

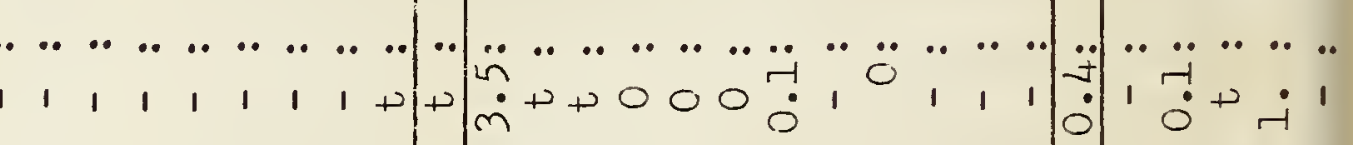

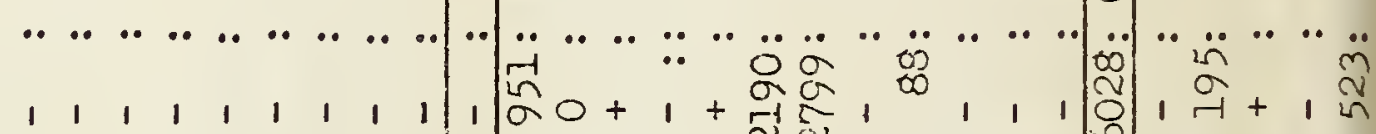

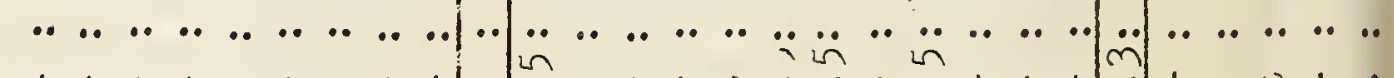

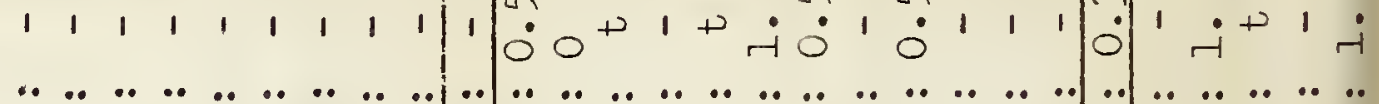

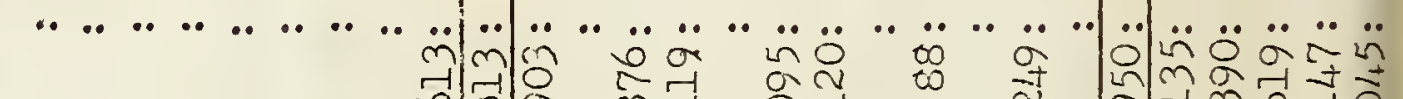

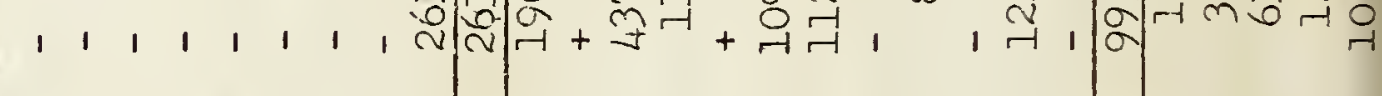

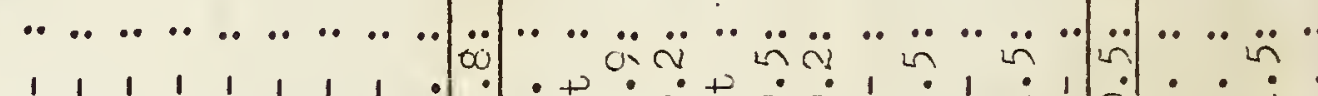

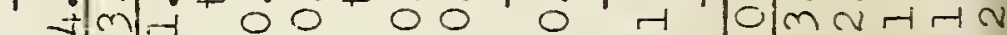

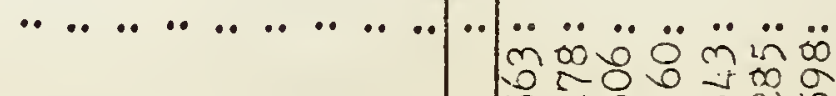

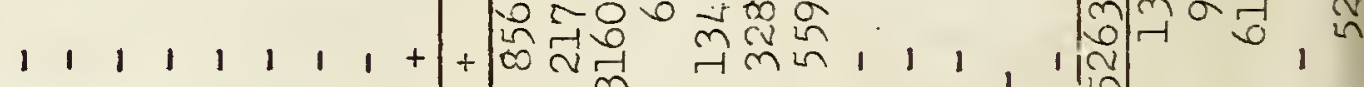

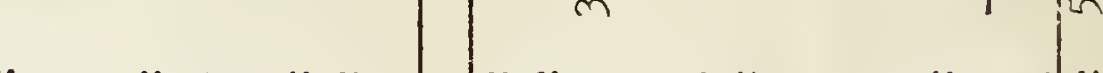

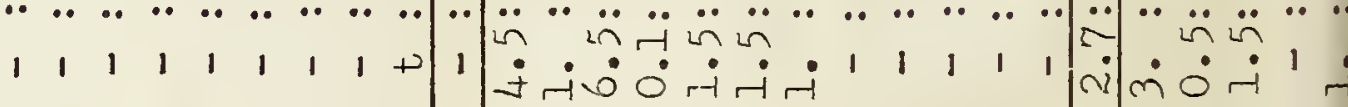
.

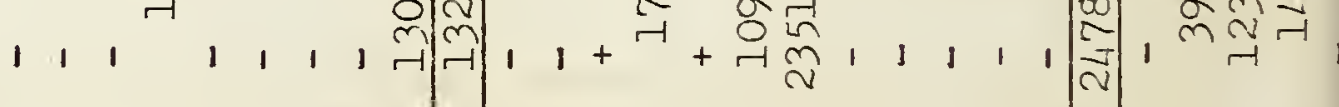

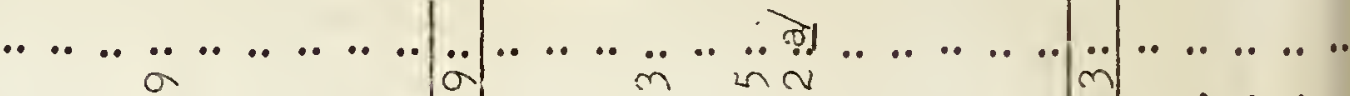

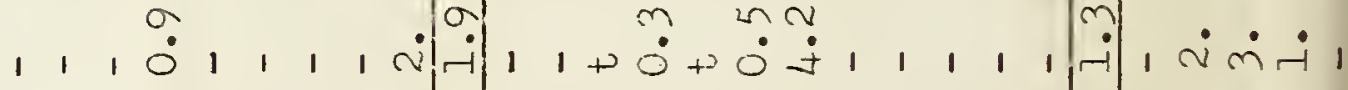
.

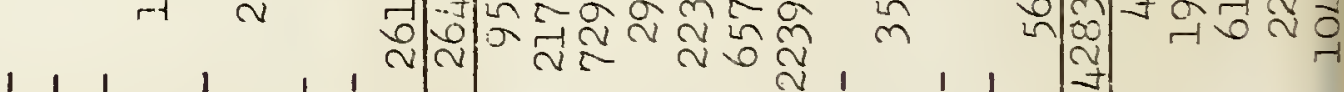

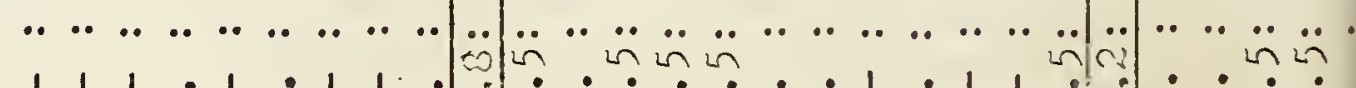

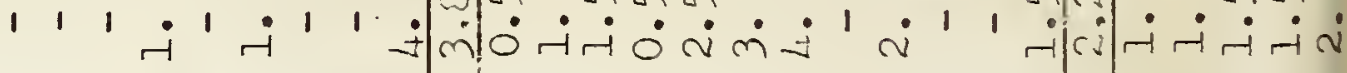

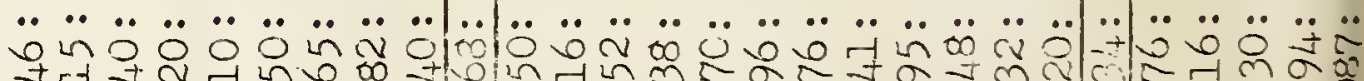

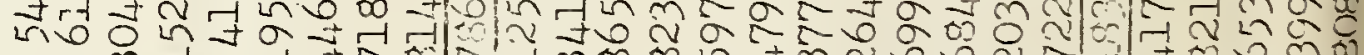

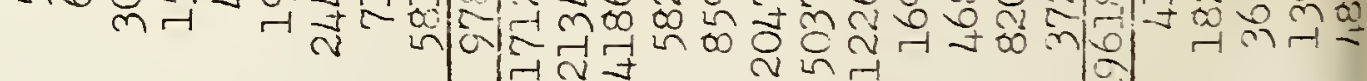

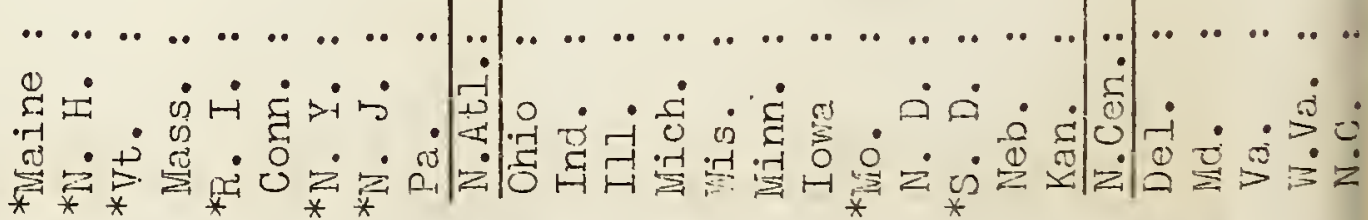




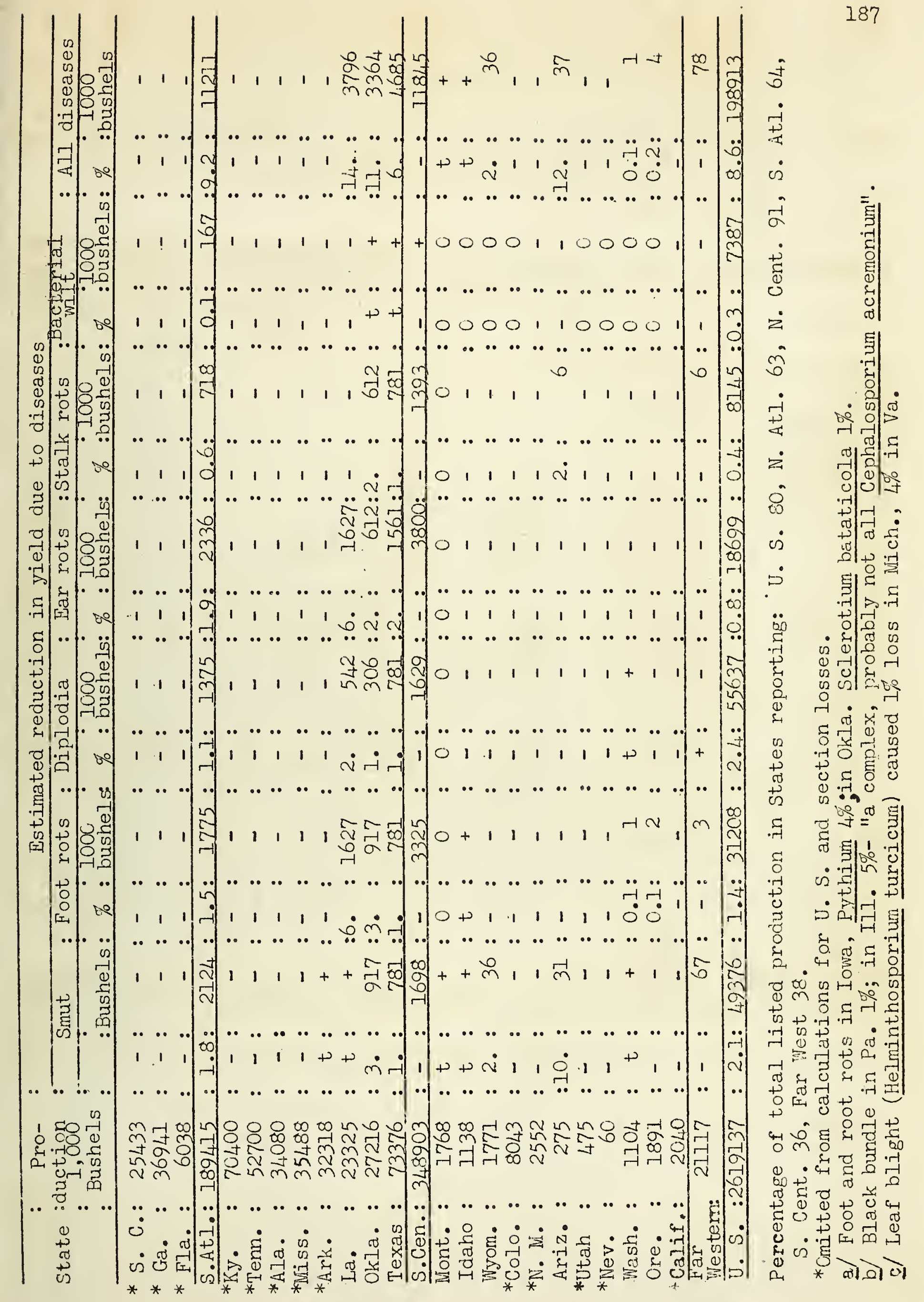




\section{SWRET CORN}

Table . Estimated reduction in yield due to smut (Ustilago zeae) bacteri.al Wilt (Phytonionis stewarti), stalk and ear rots (Diplodia spp.), foot rots and seediing blights, (Fusarium spp. and others) and other diseases, 1939.

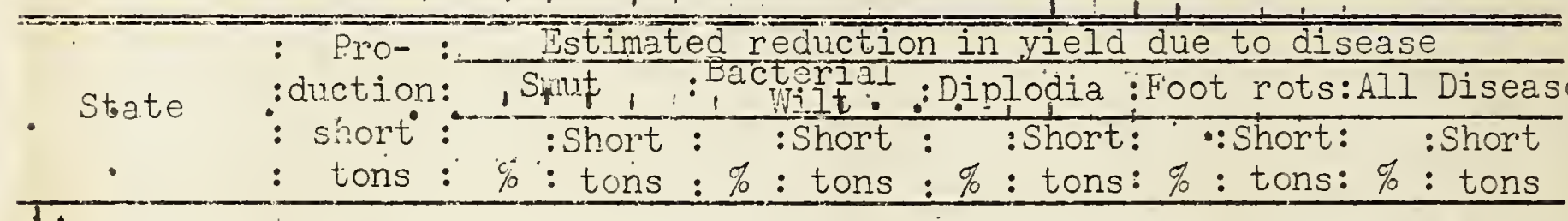

\begin{tabular}{|c|c|c|c|c|c|c|c|c|c|c|c|c|c|c|}
\hline *Maine & : & 23300: & : & - & C & & 0 & - & : & - & : & : & $:-$ & 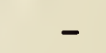 \\
\hline *New Hamoshir $\theta$ & & 400: & - : & - & $: 0$ & : & 0 & - & : & - & : & : & : - & \\
\hline *Vermont & : & 2600: & - : & - & 0 & : & 0 & - & : & - & : - & 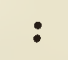 & : - & - \\
\hline Nassachusetts & : & . & 4.: & + & : $t$ & : & : & - & : & - & $: 2$ & 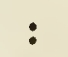 & $: 6$ & + \\
\hline New York & $:$ & $46400:$ & & 947: & : $t$ & : & $:$ & - & : & - & : - & : & $: 2$ & \\
\hline Pennsylvania & & .185 & & 841: & 5 & : & 1051: & $t$ & : & + & $: 3$ & : & $631: 12$. & 252 \\
\hline Ohio & : & $37200:$ & $0.1:$ & 38: & 2 & : & $760:$ & $t$ & : & + & $:-$ & : & $: 2.7$ & \\
\hline ana & : & 673 & 0.5 & $347:$ & 2 & : & $1388: 0$ & 0.5 & : & 347 & $: t$ & : & + & 20 \\
\hline is & $:$ & 1248 & $t:$ & & 0.3 & & 376: & - & : & - & : - & : & $: 0 . ?$ & 37 \\
\hline Igan & $:$ & $2200:$ & 0.1: & $2:$ & & $C:$ & & 0.1 & & 2 & $: 0$ & & $2: 0.7$ & \\
\hline Wisconsin &.$:$ & 42700: & 5.: & 2247: & & C: & $0:$ & $t$ & : & + & $: t$ & $:$ & $: 5$ & 22 \\
\hline sota & : & 1512 & 3. : & 4775: & & $0:$ & $C:]$ & ]. & & 592 & $: I$ & $:$ & $1592: 5$. & I \\
\hline & : & 405 & 8.: & $3733:$ & $: 0.1$ & & $47: 5$ & & & 33 & & & $: 13$. & 616 \\
\hline North Dakota & & & 3.: & + & & $\mathrm{O}:$ & $0:$ & - & $:$ & - & $:-$ & & $: 3$ & + \\
\hline aska & : & 28 & - & - & : - & : & - & - & : & - & : - & : & : - & - \\
\hline re & $:$ & 14 & 2 & $30:$ & : - & : & - & I. & $:$ & 15 & $: 5$ & : & $76: 8$. & 12 \\
\hline Tland & $:$ & 51 . & . $.5:$ & 814: & 1 & : & $543: 2$ & 2. & & .086 & :I. & & $543: 5.7:$ & 305 \\
\hline West Virginia & & & 2.: & + & :1. & : & + & - & $:$ & - & : - & : & $-\quad: 3 .:$ & + \\
\hline & : & & $0.5:$ & + & : & : & $:]$ & 1. & $:$ & + & $:-$ & : & $: 3.5$ & + \\
\hline ssee & : & & i- & $-1 \vdots$ & - & : & $i-$ & - & . & - & $: \quad-$ & : & : - & - \\
\hline$* A]$ & $:$ & $\bullet^{\bullet}$ & $t \quad:$ & + & : :- & & - & - & : & - & $:-$ & : & $: t$ & + \\
\hline & : & & $\mathrm{t}$ & + & 0 & & 0 & 0 & $:$ & - & $: 1$ & : & :I. & + \\
\hline & & & & + & $: 0$ & & 6 & - & & - & : - & : & $: 12$. & + \\
\hline ts & & & $t$ & $+\quad:$ & 0 & & : & $t$ & & + & $1::-$ & & $: t$ & + \\
\hline & & & $t$ & + & 0 & & 0 & - & 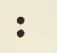 & - & $: t$ & & $: t$ & + \\
\hline
\end{tabular}

Uhited States: $647900: 2.2: 13774: 0.7: 4165: 0.9: 5375: 0.5: 2844: 4.3: 26323$

-**include Colorado, Idaho, Kansas, Kentucky, Missouri, Lontana, New Jersey, Cklahoma, South Dakota, Texas, Utah, Virginia, and Wyoming.

* Omitted from calculations for United States percentage loss

Percentage of total listed production in States reporting, 95. 


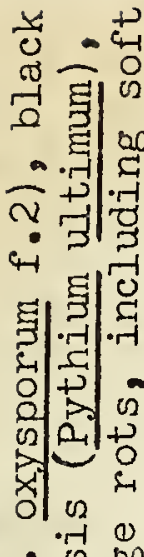

ir is 00

¿

का $\mathbb{D}_{4}+2$

जाए हैं

+3 \& क

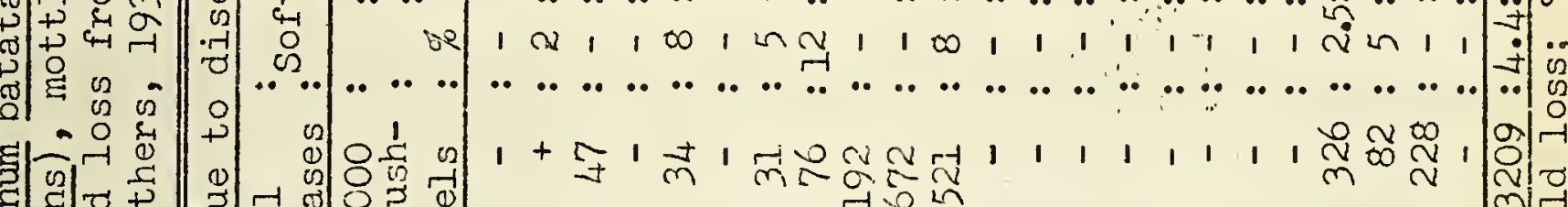

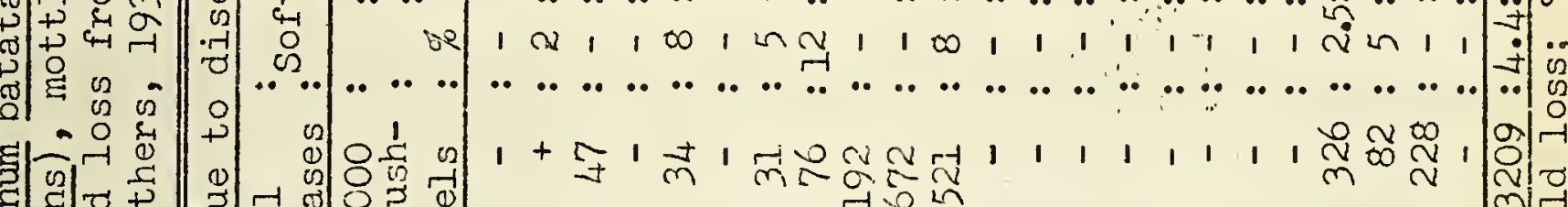

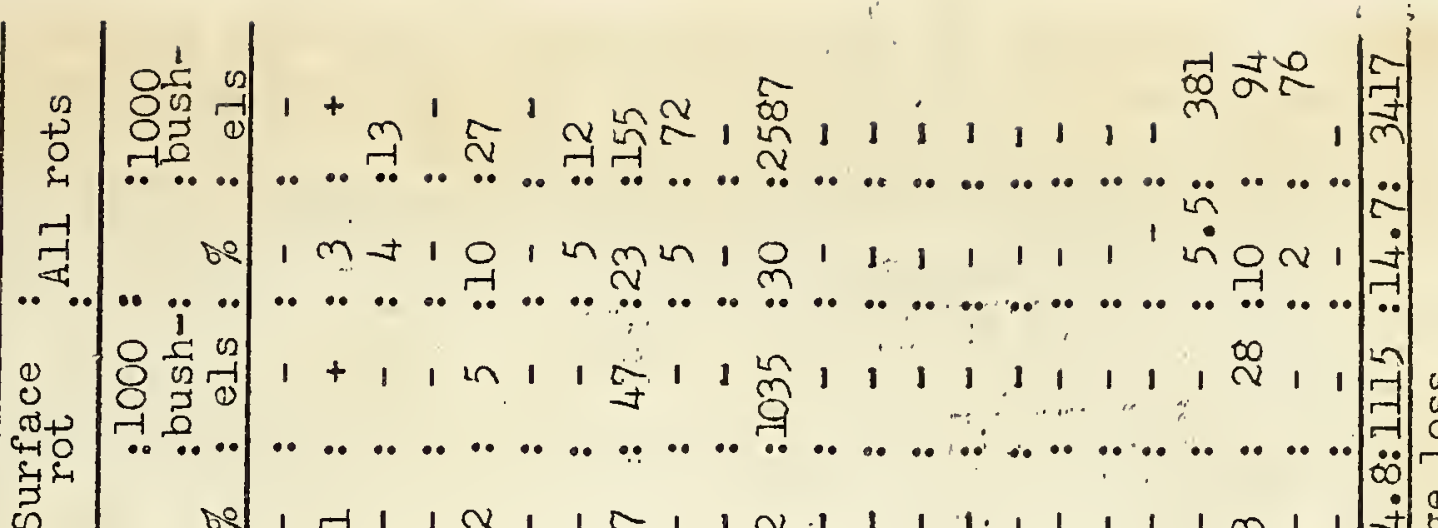
(1) ह

ad

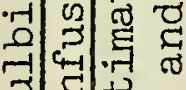

3.

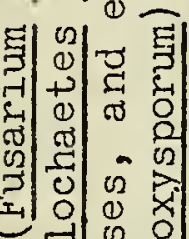

-

잉

함ㄷㄹ

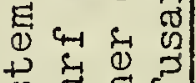

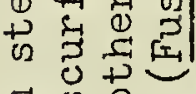

青 0

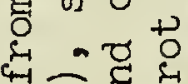

의

व.

的

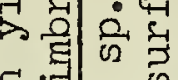

न्नंज्ञा

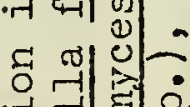

-

政

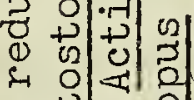

ช

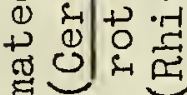

.

be … ...

$\ddot{\circ}$ 过 $\ddot{0}$

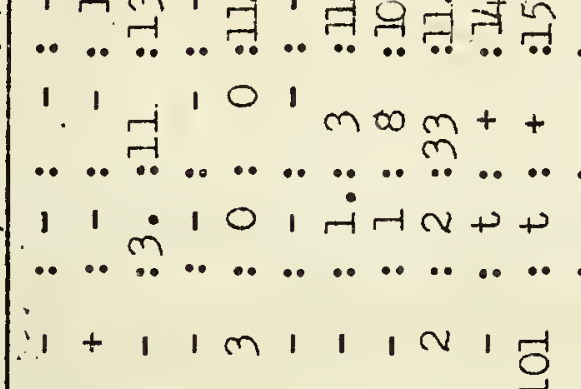

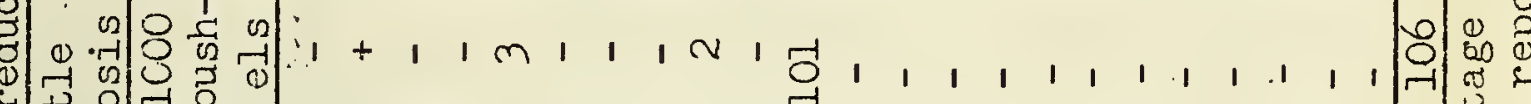

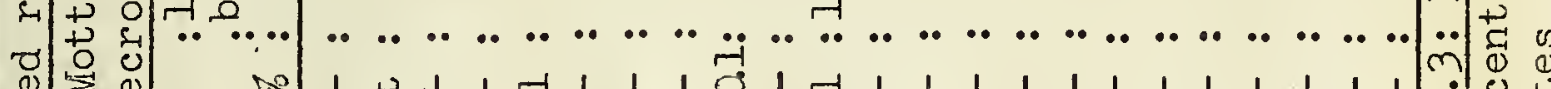

$\left.\begin{array}{llllllllllllllllllllll}0 & 0\end{array}\right]$

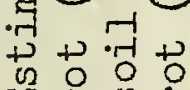
क्य \&

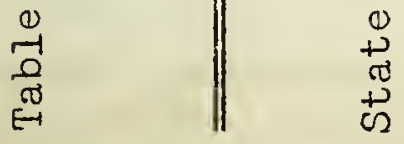

||

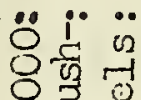

घ 10.

$111101 \mathrm{H}+\infty \frac{0}{0}$

.

be

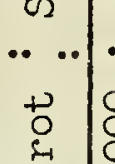

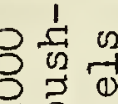

$1+$

$11+1$ 요용

1, $1,4,1,0,0$

कo

$\begin{array}{cccc} & \ldots & 0 & 0 \\ 1 & \ldots & \ldots & 0\end{array}$

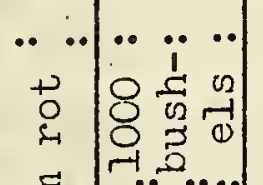

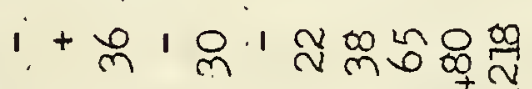

be

2

. . . . . . . . . . . . . . .

$\begin{array}{ccccccccccccc} & \cdots & \cdots & \cdots & \ldots & \cdots & . & \ldots & \ldots & \ldots & \cdots & \ldots & . \\ 1 & 1 & 1 & 1 & 1 & 1 & 1 & 1 & 1 & 1 & + & 1\end{array}$

范

$\left|\begin{array}{l}0 \\ 0 \\ 0 \\ 0\end{array}\right|$

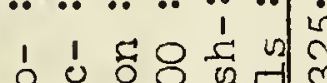

언

1

$\begin{array}{cccc}\cdots & \cdots & \cdots & \cdots \\ 1 & 1 & 1 & 1\end{array}$

,

...

.

in 0

ن.

+

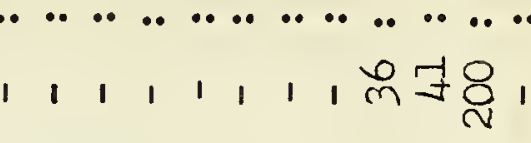

0.0

| 
Table. Reduction in yield from mosaic, leafroll, and other virus diseases (including purple top), late blight (Phytophthora infestans), rhizoctonia (‥ Solani), blackleg (Erwinia phyiophthora), fusarium wilt (Fusarium spp.),

\begin{tabular}{|c|c|c|c|}
\hline $\begin{aligned} & \text { Pro- } \\
\text { : duc- } & \text { State: tion }\end{aligned}$ & $\begin{array}{c}\text { Estimater } \\
\text { Virus djseases } \\
\text { Mosaic :Leaf roll:Others }\end{array}$ & $\begin{array}{l}\text { dreduction in yield due to } \\
\text { : Late :Rhizoc- :Black- } \\
\text { : bilight : tonia : leg }\end{array}$ & $\begin{array}{l}\text { diseases } \\
\text { :Fusarium } \\
: \text { wilt } \\
\end{array}$ \\
\hline
\end{tabular}
:1,000::1000::1000: :1000::1000::1000::1000:: :1000 :bushels: $\%:$ bu.: $\%:$ : bu. : $c_{0}:$ bu. $_{0} \%:$ bu. : \% : bu.:\% : bu.: $\%:$ bu.: Me. $: 38250: 1 .: 441: 3 .: 1322: t:+: 1 .: 441: 1.5: 661: 0.5: 220:-:-$

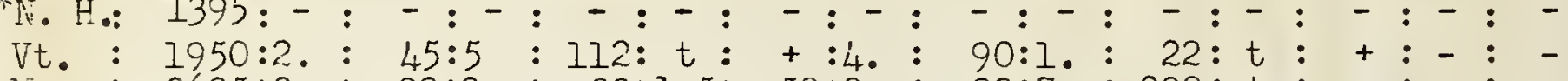

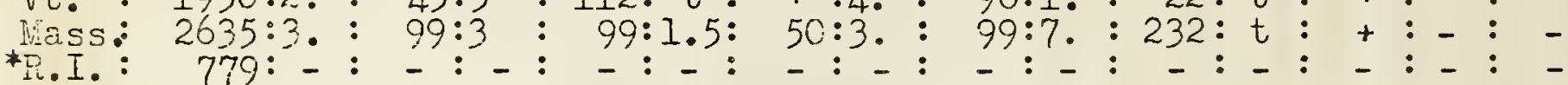
Conn.: 3238: - : - : - : - : - : - : t : + : - : - : - : - : - : N.Y.: 26797:1.: 350:1.5: 525:1.: 350:3 :1051:1.:350:t: $+: 1 .: 350$

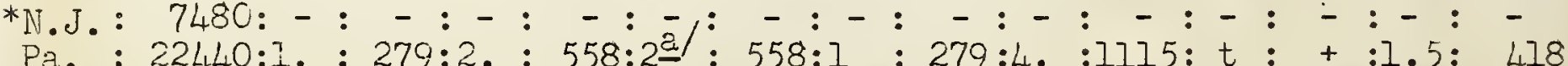
Pa.: : 22440:1. : 279:2.: 558:2a/ : 558:1 : 279:4. :1115:t: $+: 1.5: 418$ $\frac{1.4 t 1: 104904: 1 .: 1214: 2.3: 2616: 0.8: 958: 1.7: 1900: 2.1: 2380: 0.2: 220: 0.7: 768}{\text { Ohio: } 12600:-:-: 4 \cdot: 599: t:+: 0.3: 45: 0.5: 75: t:+1 .: 150}$ Ind.: $4560: C_{01}: 6:-:-: t:+: 5: 275: 2$. $: 110:-:-:-:$ *Ill.: 3441: - : - : - : - : - : - : - : - : - : - : - : - : Mich: $24250: t:+t t:+t t:+: 3.5: 1065: 0.3: 91: 1: 304: 0.3:$ Wis.: $17336: 1 .: 200: 0.5: 100: 5 .: 1002: 30: 601: t:+: t:+t 1:: 200$

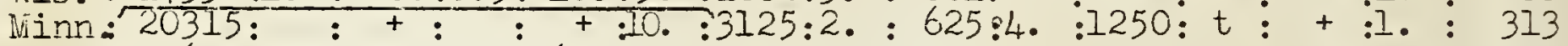
Iowa: $5600: 8 .: 700: 7 .: 613: 2$. : 175:t $:+: 4 .: 350: 0.5: 44: t:+$

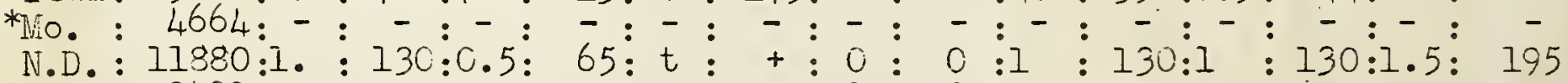
*S.D.: 2400:- : - :-: - : - - $0: 0:-:-:-:-:-:-$

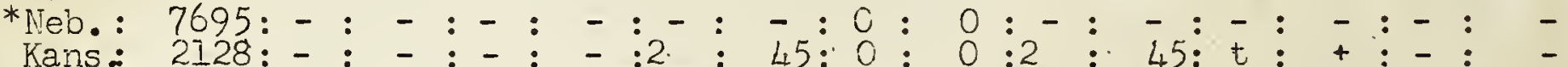

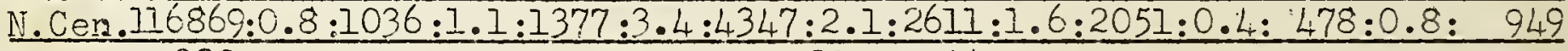

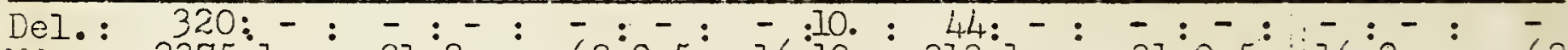
Mel.
Ma. $2375: 1$.
Va. $6786: 1$

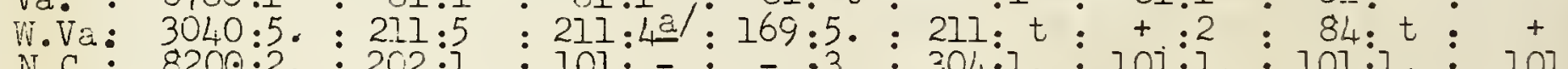
N.C.: 8200:2. : 202:1. : 101:- - :3.:304:1. : 101:1. : 101:1. : 101 *S.C.: 3108: - : - : - : - : - : - : - : - : - : - : - : - : - : -

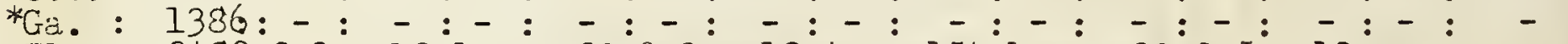
Fla.: $3480: 0.3: 12: 1 .: 39: 0.3: 12: 4 .: 154: 1 .: 39: 0.5: 19:-:-10$ F.Atl.28695:1.8:537:1.7: 494:0.9:278:3.4:1026:0.8:252:1.: $301: 0.5: 163$ *Tenn: 2911: - : - : - :

*Aia: $4860:-:-:-:$

Ark.: 3003: - $:-:-\quad-:-:-:-:$

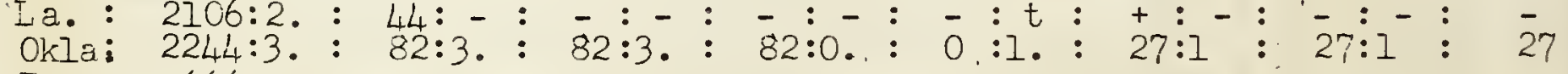

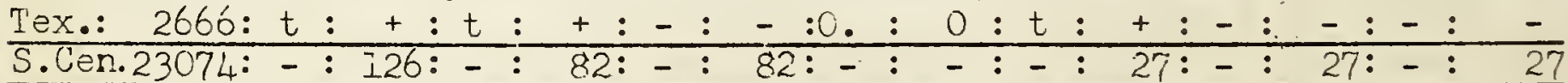

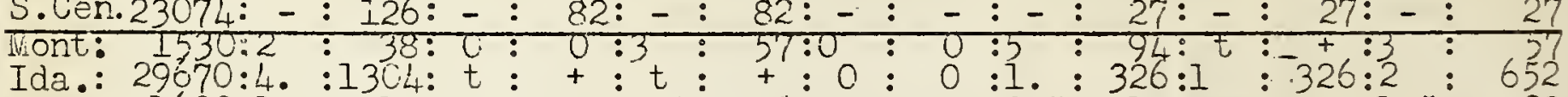

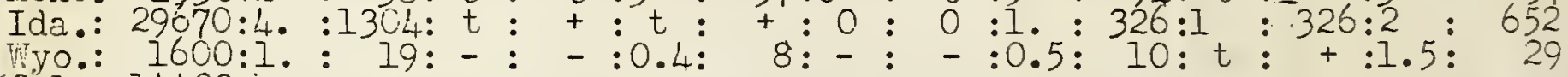
*Colo: $144000^{1}-\vdots-\vdots-\vdots-\vdots-\vdots-\vdots-\vdots-\vdots-\vdots-\vdots-\vdots-$

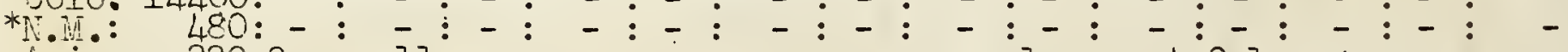
Ariz: 220:3. $: 11:-\vdots-\vdots-\vdots-\vdots-\vdots-\vdots 1 \div 4: 0.1+\vdots-\vdots-$

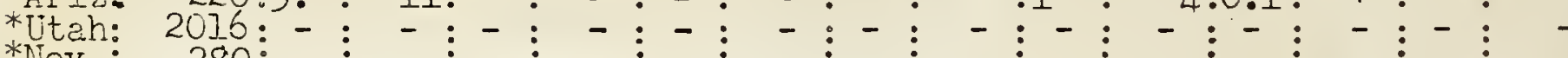

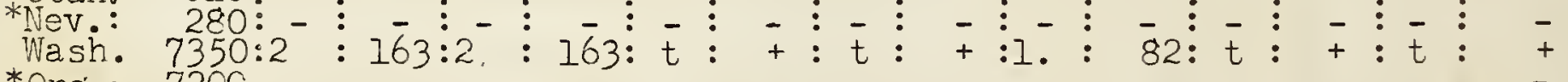
*Ore : 7200:- : - : - : - : - : - : - : - : - : - : - : - : - : -

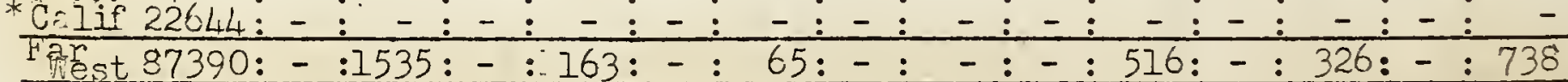
U.5:: $360992: 1.4: 4448: 1.5: 4732: 1.8: 5730: 1.7: 5597: 1.6: 5226: 0.4: 1352: 0.8: 2645$ 

Table (Cont'd.) tipburn and hopporburn (nonperasitic and leafhoppers),

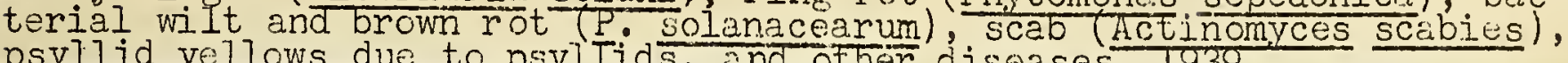
psyllid yellows due to psyllids, and other diseases, 1939.

State Tipburnand Early : Ring :Bacterial: $\frac{\text { Estimated reduction in yield due to diseases }}{\text { :Psyllid: }}$

State :hopperburn: blight: rot : wilt: Scab :yellows: diseases

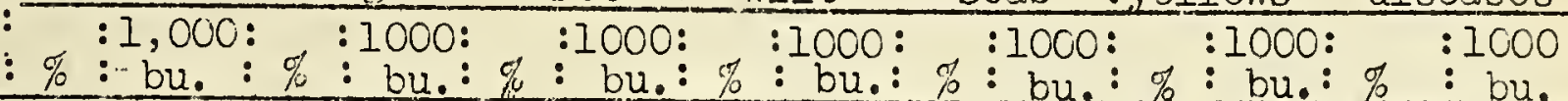

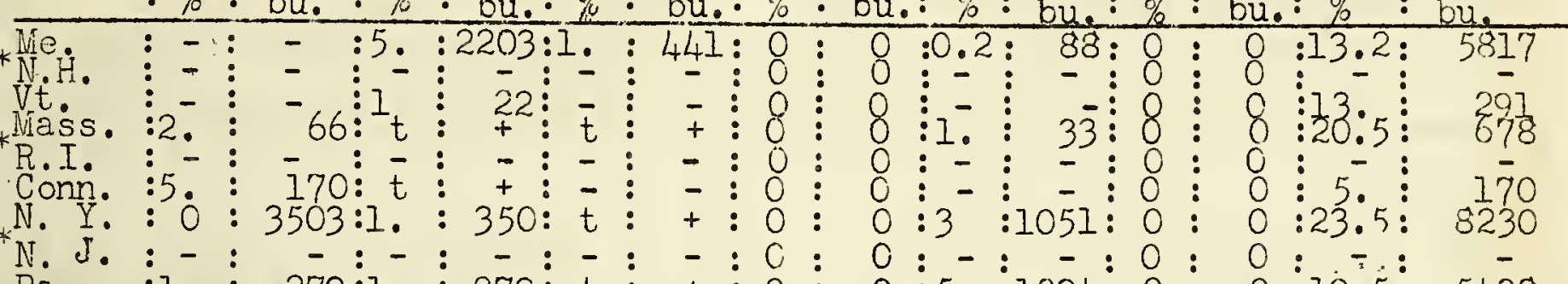

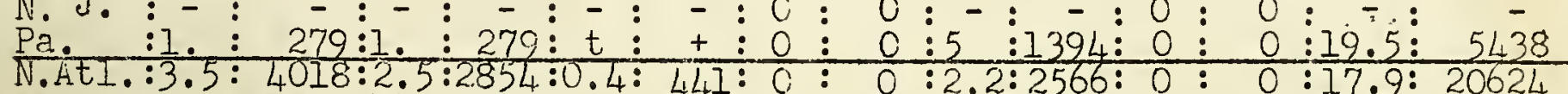
Ohio :? : 1047:2 : 299: $t:+:-:-: 1 \cdot: 150: 0: 0: 15 \cdot 8: 2365$

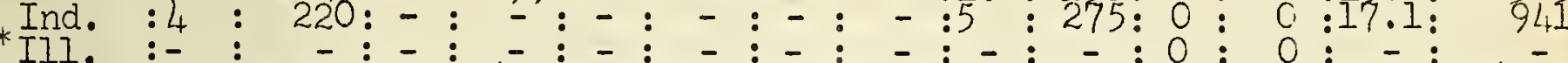

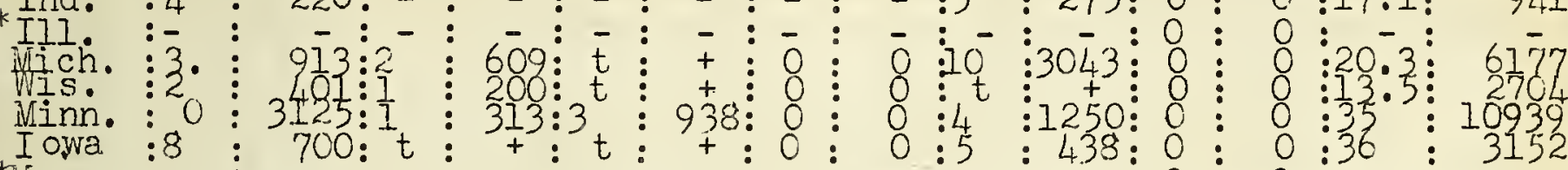

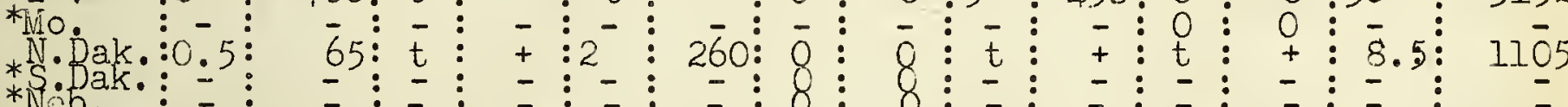

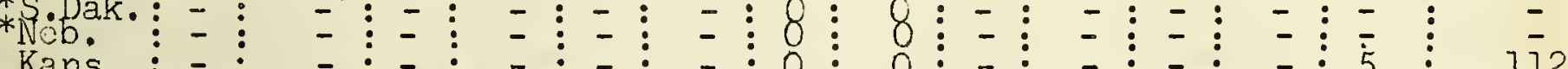

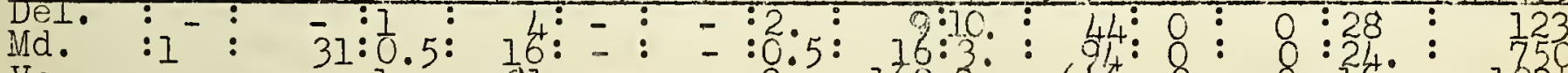

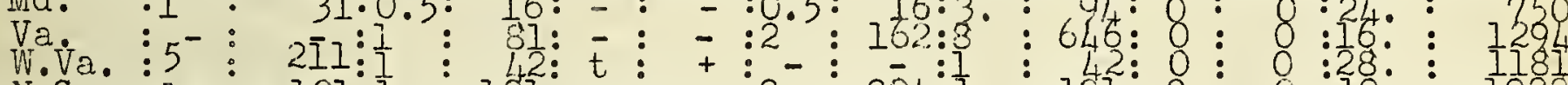

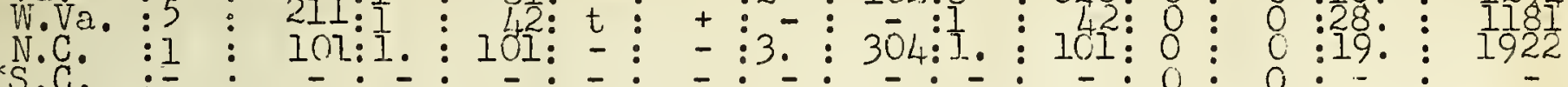

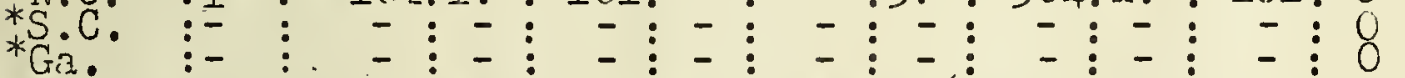

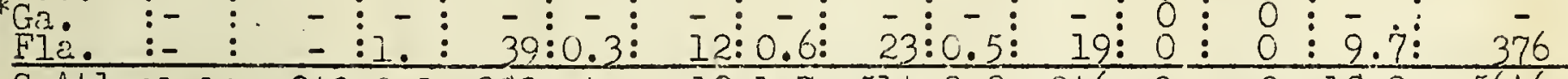

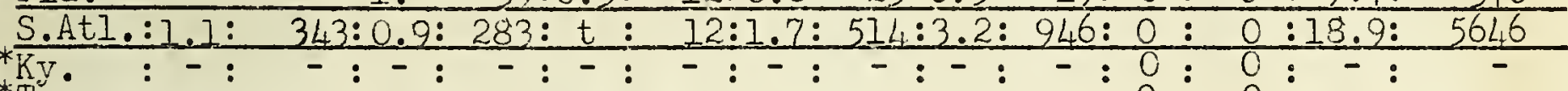
*Tron

*A.

Li. $\begin{array}{l:c}\text { Ukla. } & - \\ \text { Tex. } & t \\ \text { S.Cent }- & -\end{array}$

Nont : $\mathrm{C}: \mathrm{O}: 0:$

* utah

Nev.

*Ore.

: $\quad=-\bar{c}$

West: $-\because-\cdots-26$ :

2a:

$28:-$

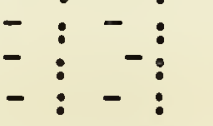

$\overline{-}: \overline{\mathrm{z}}$ $-\div 0$

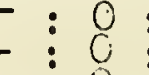

$\mp 8$

$55:-142$

$0:-$

$8 \vdots 4^{-} \vdots$

- $\vdots-\vdots 18$

$\overline{8} 8$

491

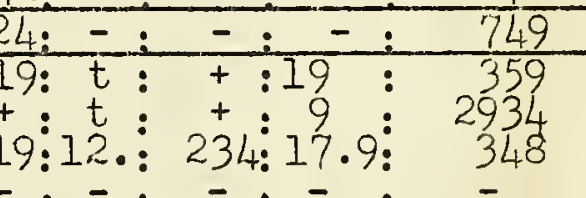

153

$-$

816

3:10832:1 $14: 16344: 06$

* Omitted from calculations for U. S. and section percentage loss.

Percentage of total listed production in States reporting:

U. S. 74, N.AtI. 91, N.Cent. 34, S.AtI. 84, S.Cent.30, Far West 46. a/ Purple top. 
Table . Estimated reduction in yield from septoria blight ( . lycopersici), fusarium wilt ( $\mathrm{E}$. bulbigenum lycopersici), early blight and nailhead spot (Alternaria spp.), root knot (Heterodera marioni), fruit rots (various organisms).

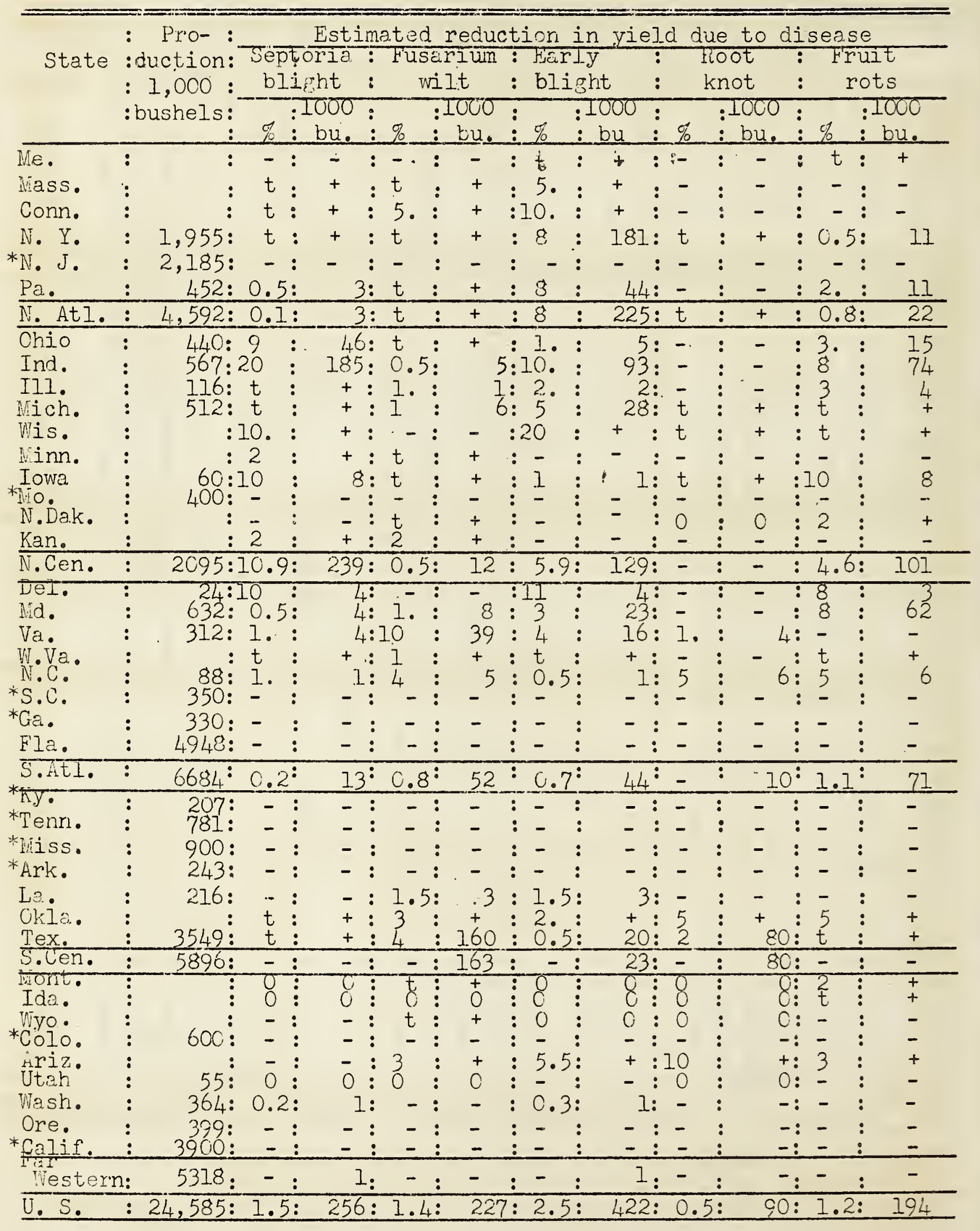


Table (cont'd.) BJossom-end rot (non-parasitic), bacterial canker (Phytomonas michiganensis), mosaic, curly top, and other virus diseases, and other diseases, 1939.

Estimated reduction in yield due to diseases

State : Blossom : Bacterial:__ Virus djseases___: All

State : end rot: canker: Mosaic :Curly top: Cthers. diseases

$: 1000:: 1000: \quad: 1000: \%: 1000:: 1000:$ : $: 1000$

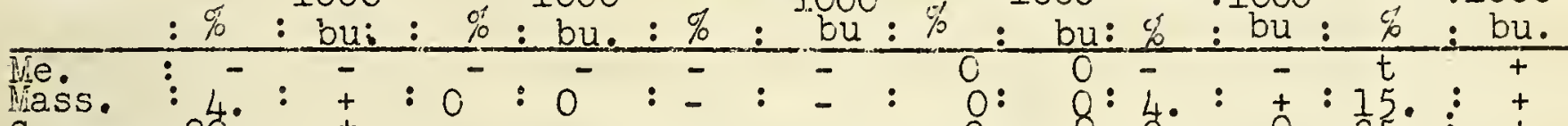

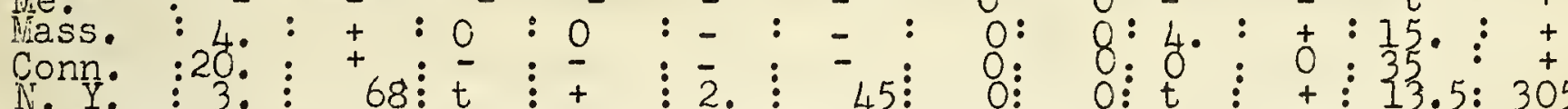

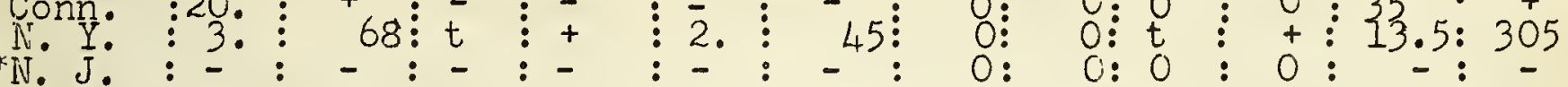

Pa. $: 5 .: 27: 0.5: \quad 3: 1: 5: 0: 0: t \quad+2: 17: 93$

N.AtI.: 3.4: 95:0.1: 3:1.8: 50: $0: 0: t:+: 14.2: 398$

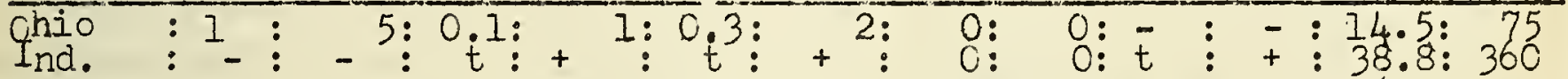

IIl. $:-:-! t:+\leq t \leq+\leq 0: 0:-\leq-\leq 6 .: 7$

Mich. $: t:+: t:+\leq t:+\leq 0: 0: t:+: 7: 40$

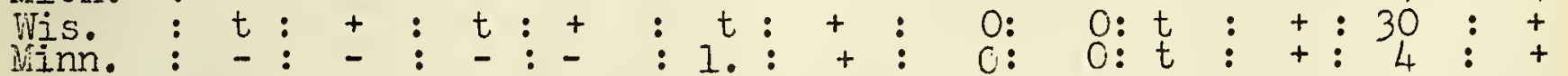

Iowa $: 3: 2: t:+:-:-: 0: 0: 2: 2: 26: 21$

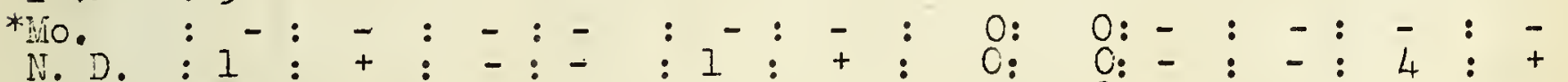

Ken. : - : - : - : $\quad:-:-: 0: 00: \vdots-: 4:+$

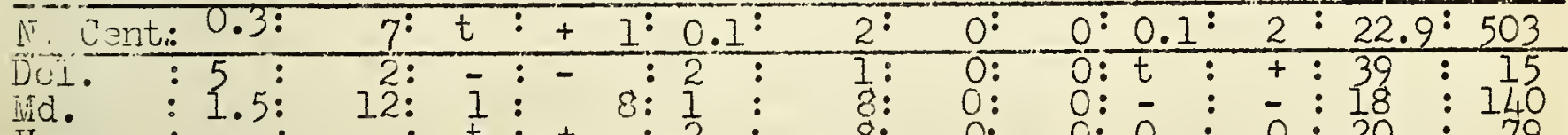

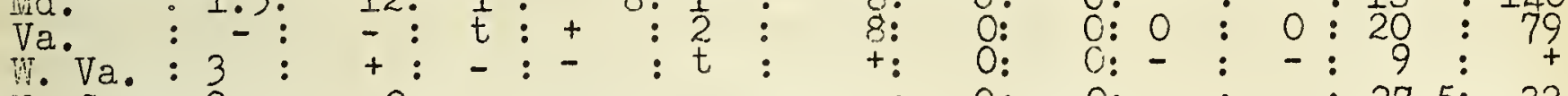

N. C. $: 2: 2:-:-\quad-\quad: \quad-: 0: 0:-\quad-\quad 27.5: 32$

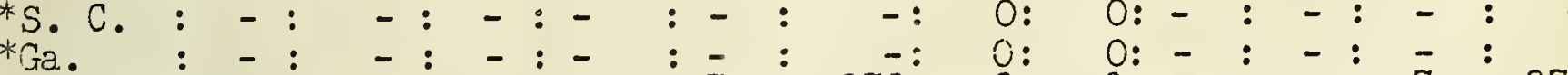

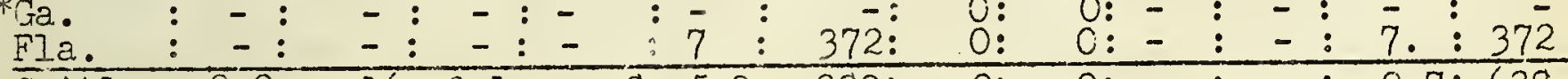

S.At]. $0.2: \quad 16: 0.1: \quad 8: 5.9: 389: 0: 0:-: - \pm 9.7: 638$

* Ky. : - : - : - : - : - : - : $0: 0:-:-:-$ :

*Tenn. : - : - : - : - : - : - : C: $0:-$ : - : - :

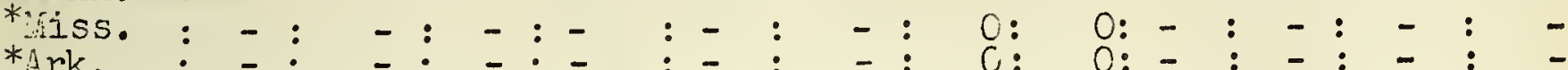

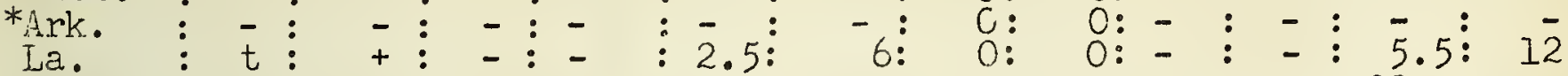

Okla. $: 3:+: t:+: 3:+00: 0: t:+22:+$

Teyas. : I: $40: t:+: t: t: t: \pm t:+: 11.5: 460$

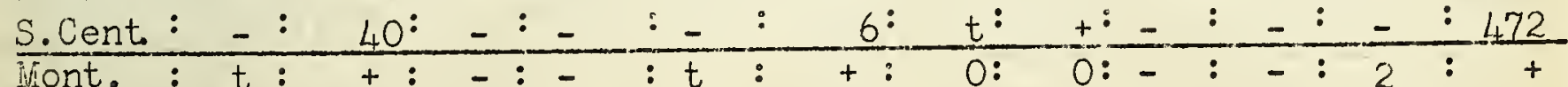

Ida. $: t:+: \bar{c}: \overline{0}: t:+5:+t:+: 5: t+$

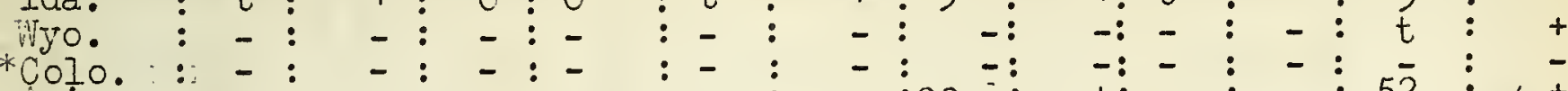

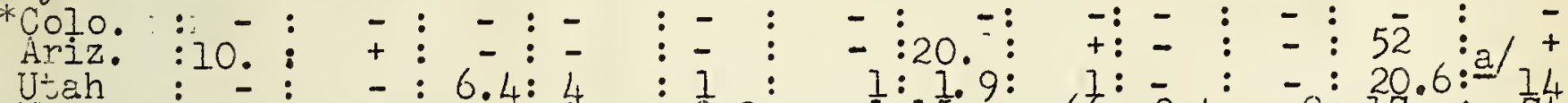

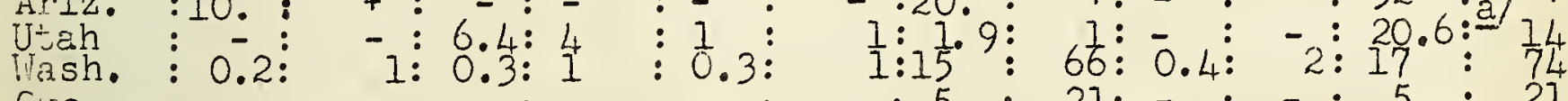

iee. : - : - : - : - :- : - :5: 21: - : - : $5: 21$

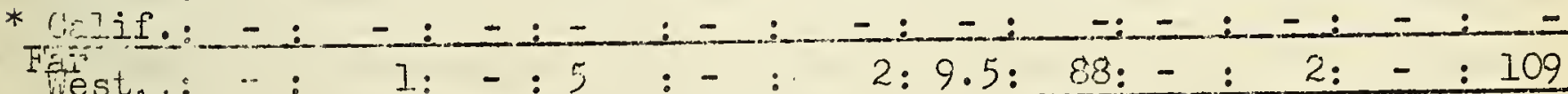

U.S. : $0.9: 159: 0.1: 17: 2.7: \quad 442: 0.5: 88: t: 4: 12.6: 2120$

*Cmitted from calculations for U. S. and section percentage loss.

Percentage of total listed production in States reporting: U.S. 60,

1. AtI. 52, H. Cent. 31, S.AtI. 90, S. Cent. 64, Far West 15.

a//Verticillium wilt ( $\underline{V}$. albo-atrum), in Utah 11.3 percent, 7,797 bushels. 
194

TGLIATCES: FOR MANUFACTUPE

Table . Estimated reduction in yield from septoria blight ( . Iycopersici.), fusarium wilt ( $\underline{F}$. bulbigenum lycopersici), early blight and nailhead spot (Alternaria solani and A. tomato), f'ruit rots due to varicus organisms.

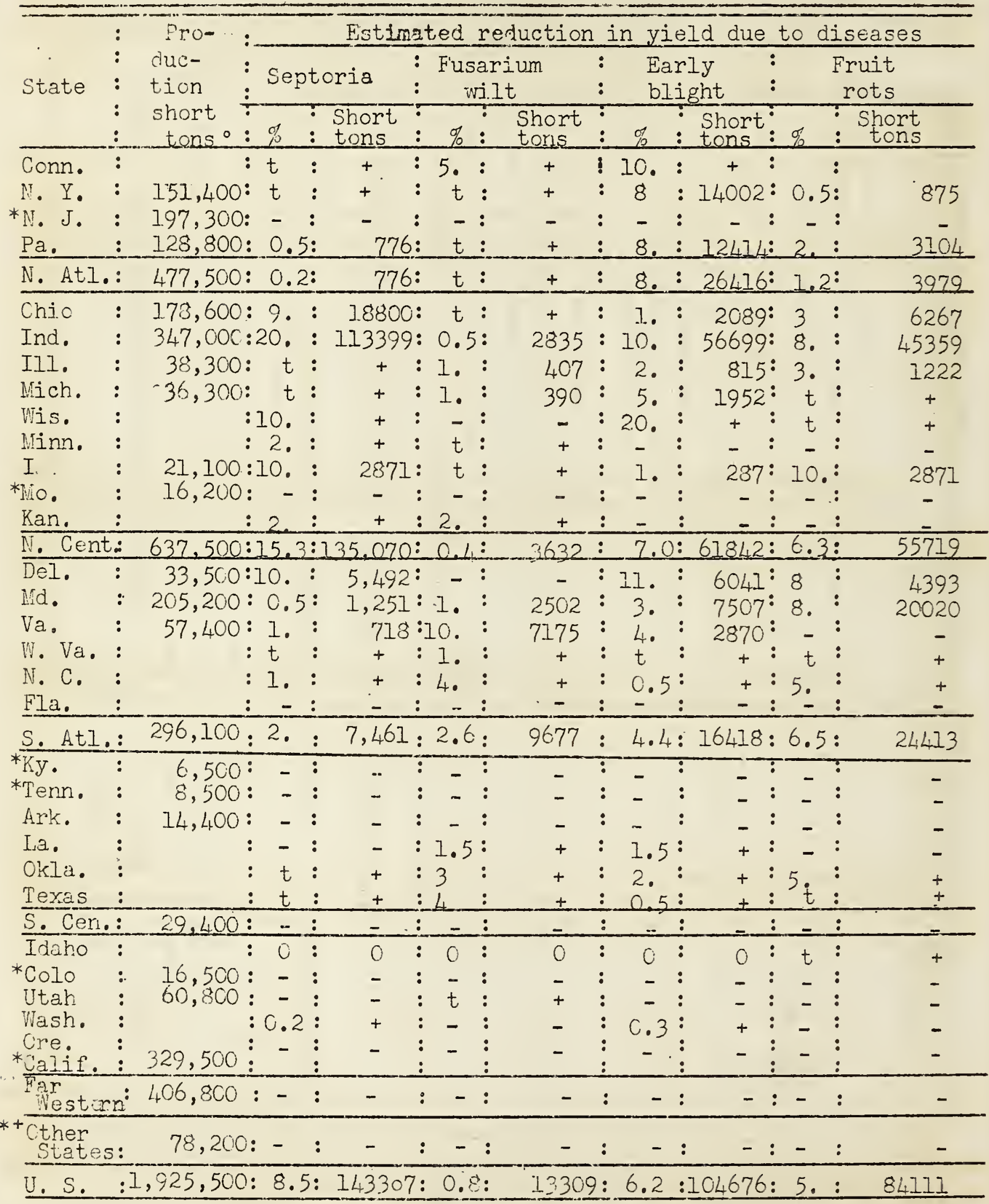


TONATOES: FOR MANUFACTURE (Continued)

Table (Cont'd.) Blossom-end rot (non-par.), bacterial canker (Phytomonas michiganensis), virus diseases //, and other diseases, 1939.

$\longrightarrow$

Estimated reduction in yield due to disease

State

: Blossom-end : Bacterial

canter

Virus

diseases a/ :

AII

diseases

$: \%$. tons $\%:$ Short : $\%$ : Short : $:$ : Short

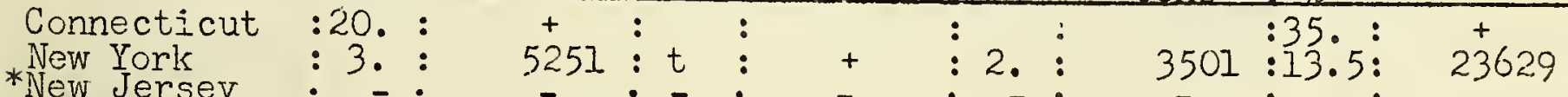

Pennersey:

N. Atzantic : $3.9: \quad 13010: 0.2:$

Ohio

Indiana

Illinois

Michigan

Wisconsin

Minnesota

Iowa

*issouri

Kansas

N. Central : 0.3 :

Delaware

Maryland $1.5:$

West Virginia $3^{-}:$

North Carolina

Florida

S. Atlantic : 1.7:

* Fientucky

*Tennessee

Arkansas

Louisiana

Cklahoma

Texas

$\vdots^{1}{ }^{\overline{0}}{ }^{1}{ }^{1}$

S. Central

Idanio

*Colorado

Utah

Washington

Cregon

*California

:

Far Western

+other states:

2089:0.1:

$-\vdots t^{1} \vdots$

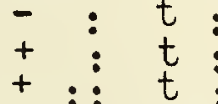

$\bar{s} 1 \vdots \bar{t}$

- : - : + - 2 .

$-776: 1 .:$

$1552: 177^{-}$

$2 \overline{6} 381$

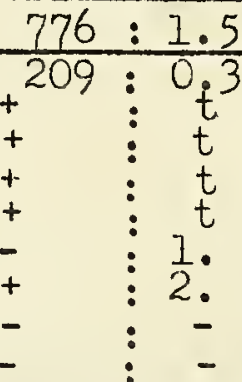

$5053: 15.1:$

50010

$627: \frac{14}{5}: 5: 230290$

$+\quad \vdots 38: 8: 219993$

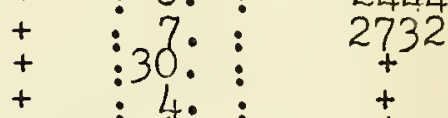

$574 \vdots 26.5$

$\stackrel{+}{7608}$

$-\quad: \quad-:$

United States: $1.5: 24836: 0.5: \quad 8450: 0.8: 13538: 24.5: 412240$

- Short tons, 2000 pounds

* Omitted from calculations for U. S. and section percentage loss. Percentage of total listed production in States reporting: U. S. 66, N. Atl. 59, N. Cent. 97, S. Atl. 1C0, S. Cent. 49, Far West 15.

+Include Ala., Conn., Fla., Ga., Ida., Kan., La., Minn., Miss., Neb., New Mexico, N. C., OkIa., Ore., S. C., Texas, Wash., W. Va., and Wis.

a/ Except in the Far West, mosaic, except traces of streak in N. Y., PE., Wis., Okla., and Tex., traces of spotted wilt in Mich., Del., and Texas, and trace of curly top in Texas. In the Far West, curly top except mosaic, trace in Idaho, $1 \%$ in Utah, $0.3 \%$ in Wash.; spotted wilt, $0.2 \%$ in Wash.; streak, trace in Idaho, $0.2 \%$ in Wash.

b/ Verticillium wilt (V. albo-atrum): Del. I \%, 549 short tons;-Utah 11.3\%, 8763 short tons; Wash. $0.3 \%$. 


\section{GREEN BEANS}

Table . Reduction in yield from anthracnose (Colletotrichum lindemuthianum), becterial blights (Phytomonas spp.), virus diseases (mostly mosaic), rust, (Uronyces phaseoli typica), powdery mildew (Erysiphe polygoni), and other diseases, 1939 .

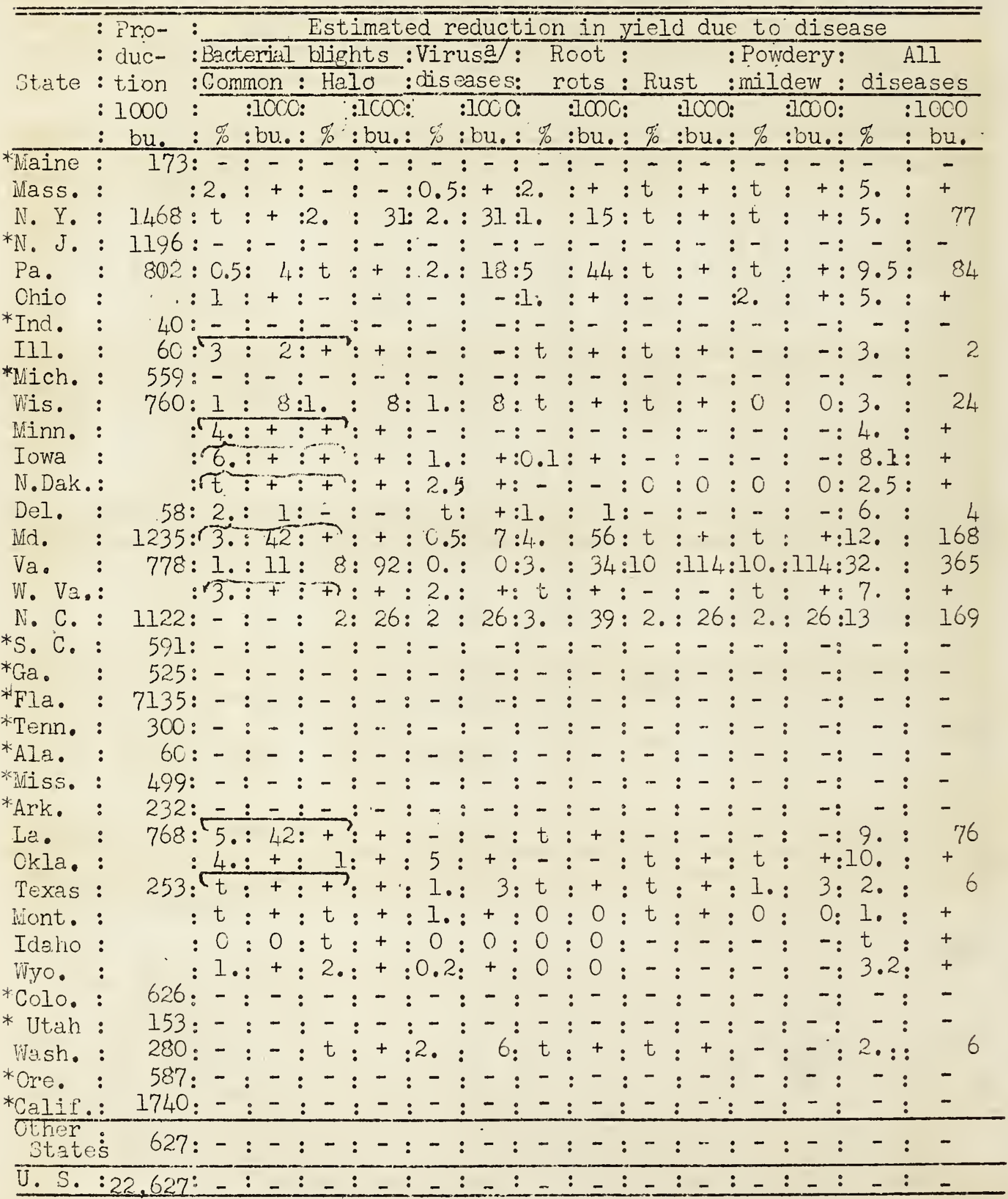

Data not sufficient to calculate U. S. percentage loss.

Percentage of total listed production in states reporting. 36. 
Table . Reduction in yield frum bacterial blights (Phytcmonas spp.), virus diseases, root rots (various organisms), and other diseases, 1939.

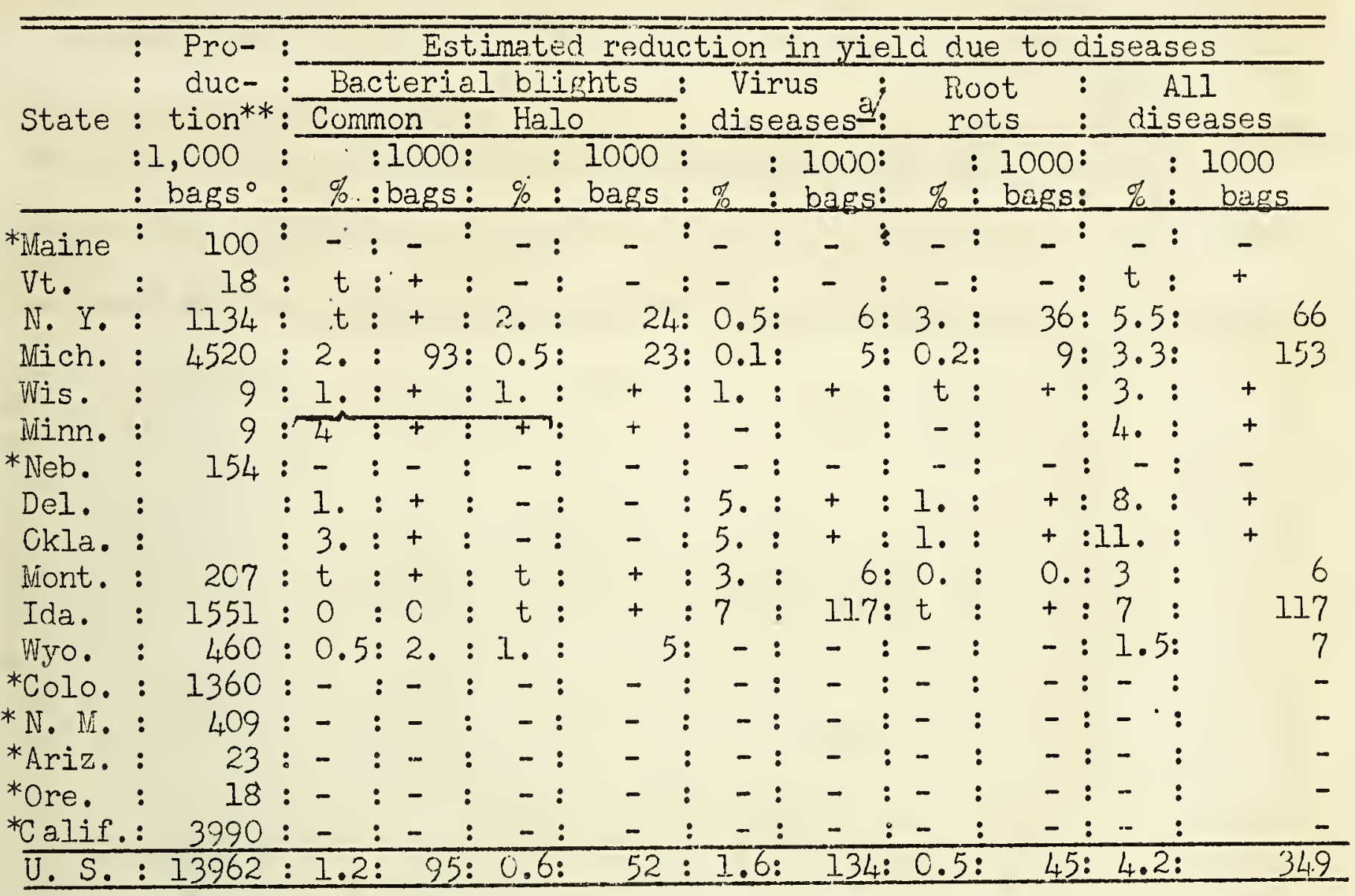

* Omitted from calculations for U. S. percentage loss

Percentage of total listed production in states reporting, 57.

a/ Mosaic, except Idaho, mosaic $5 \%$, curly top, $2 \%$.

**Includes beans grown for seed.

- Bags of 100 pounds. 
GREEN PEAS FOR MANUFACTURE

Table - Estimated reduction in yield from wilt and near wilt (Fusarium spp.), ascochyta blights (iycosphaerella pinodes and Ascochyta spp.), root and stern rots caused by various organisms, virus diseases, and other diseases, 1939.

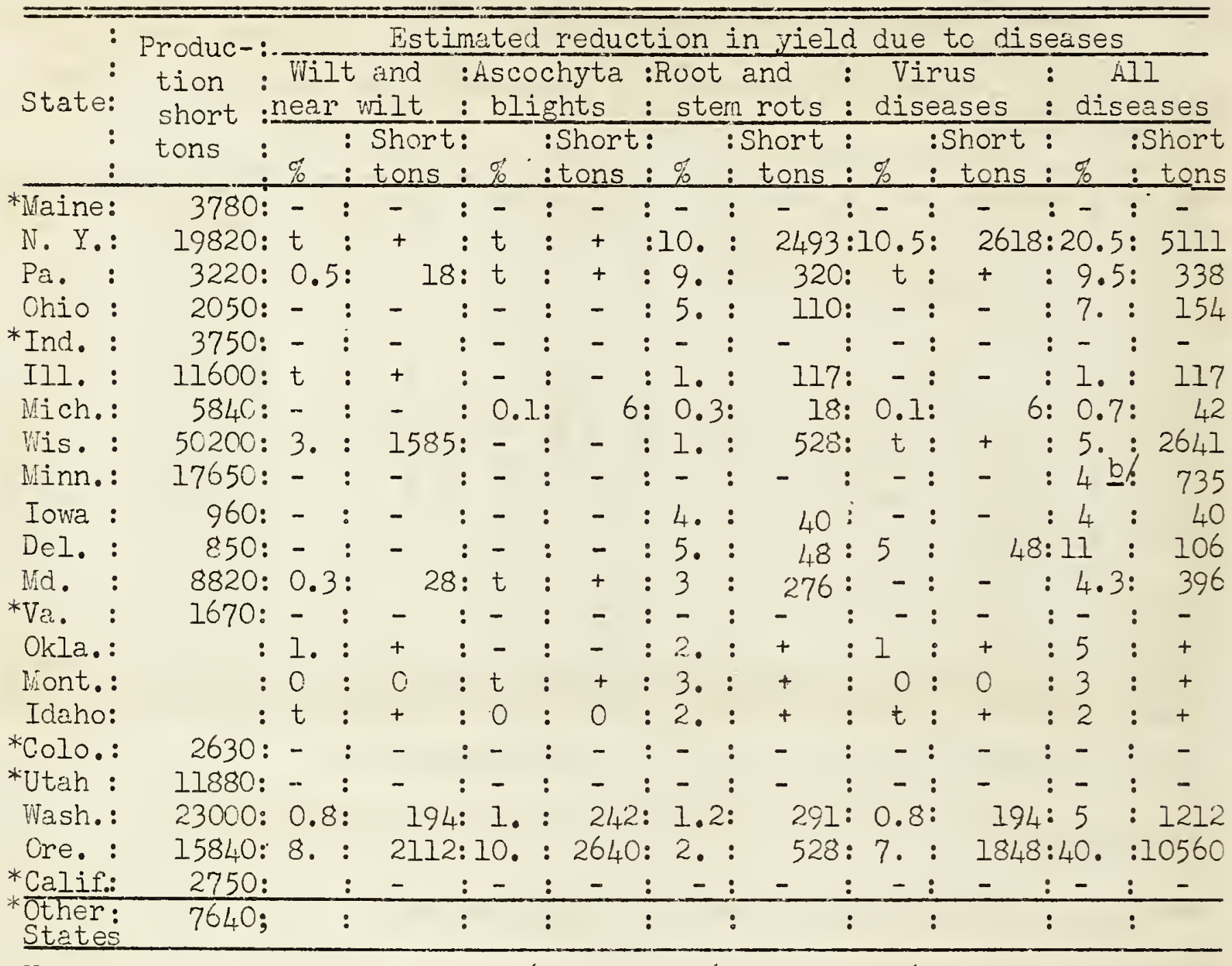

U.S.: 193950:2.2: 3937: 1.6:2888:2.6: 4769:2.6: 4714:11.8:21452

* Omitted from calculations for U. S. percentage loss.

Percentage of total Iisted production in States reporting, 82. a/ Nosaic, except streak $0.5 \%$ in $N . Y ., t$. in Idaho, $0.4 \%$ in vash. b/Bacterial blight (phytomonas pisi) 
Table . Estinated reduction in yield from wilt and near wilt (Fusarium spp.), ascochyta blights (Mycosuhzerella pinodes and Ascochyta spp.), root and stem rots caused by various organisms, virus diseases, and other diseases, 1939.

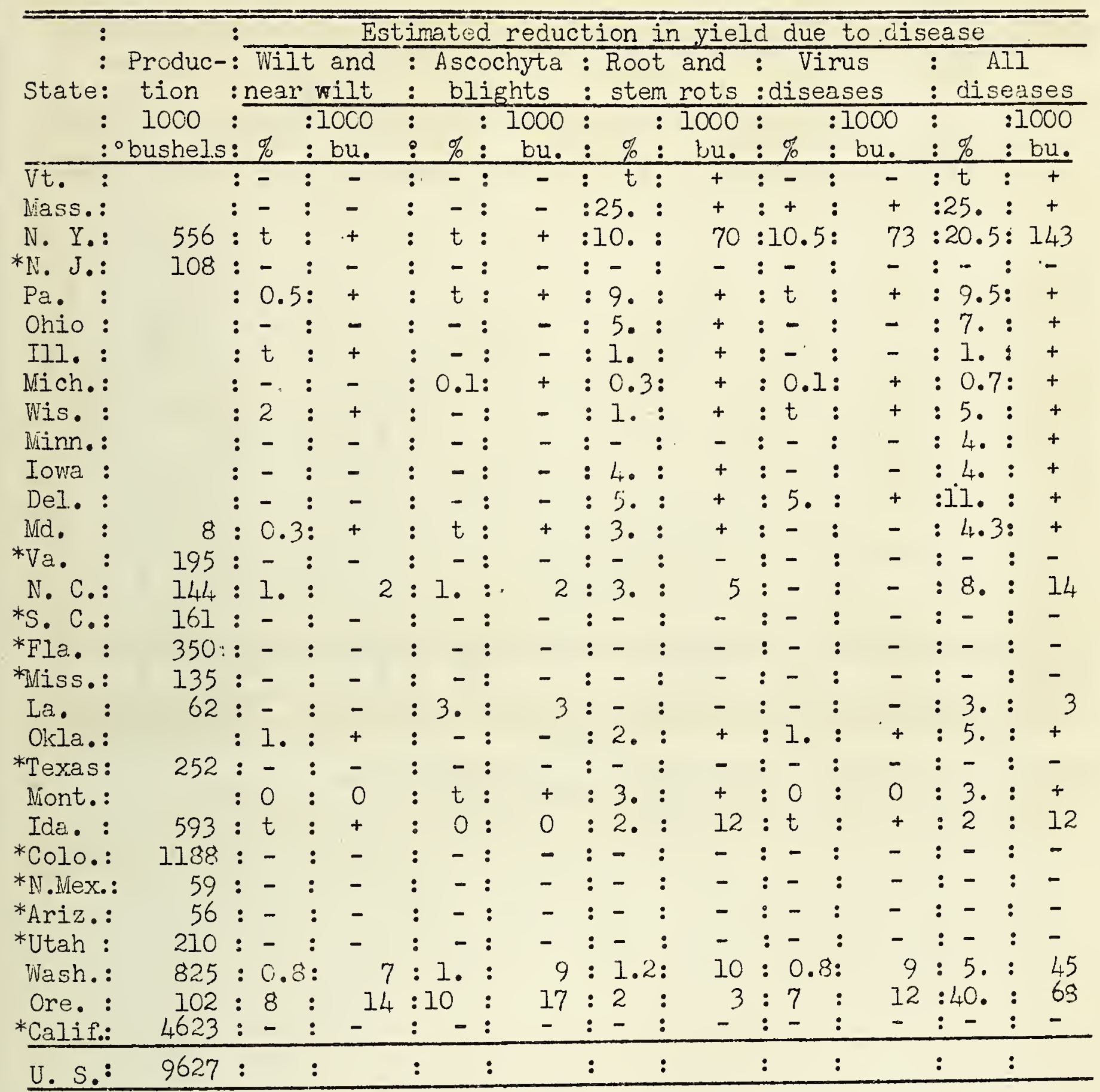

- Bushels of 30 pounds.

Data not sufficient to calculate U. S. percentage.

Percentage of total listed production in States reporting, 24. 
Table - Estimated reduction in yield due to curly top (virus), leaf spot (Cercospora beticola), root rots (various organisms), damping-off (various organisms), and other diseases, 1939.

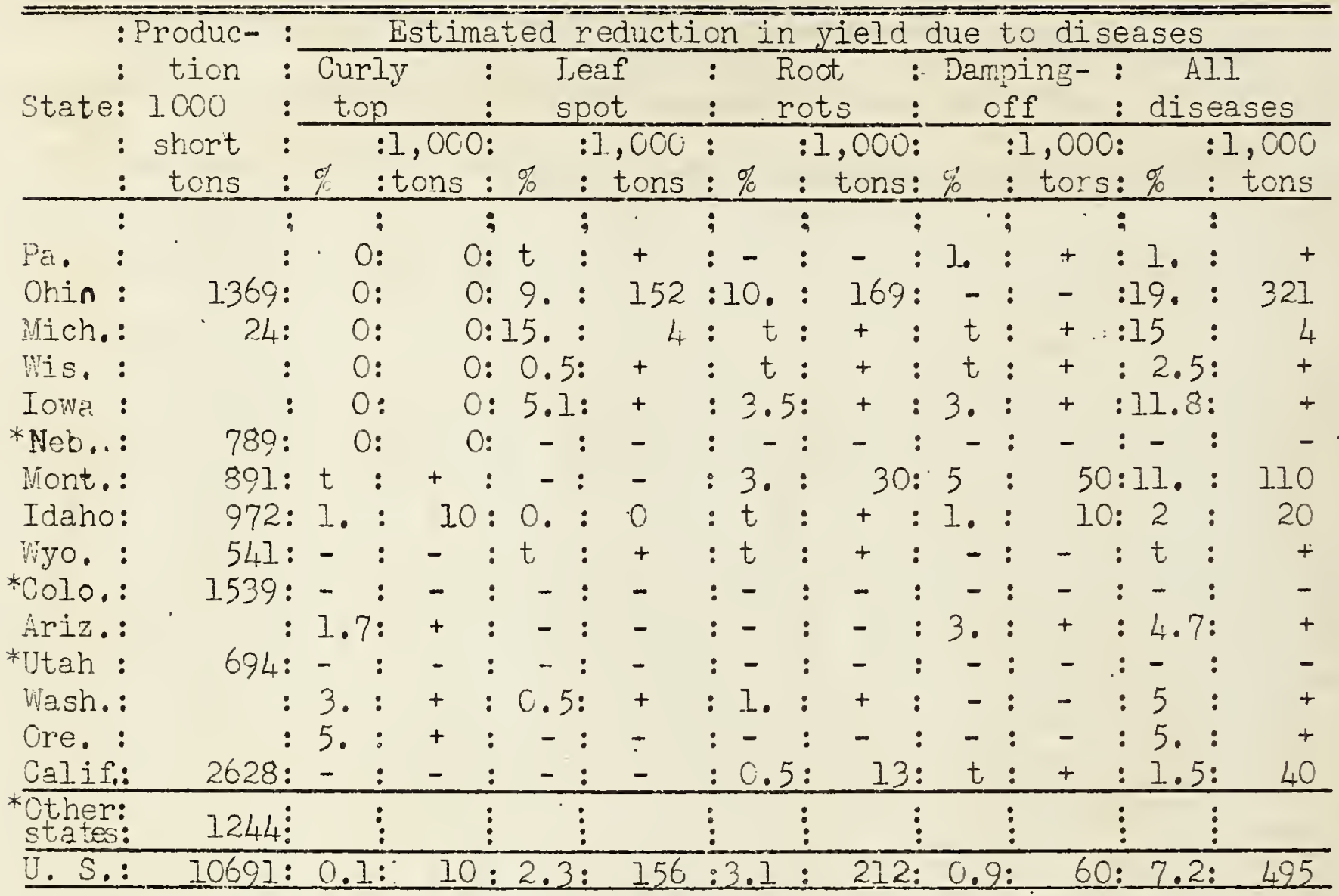

* Onitted from calculations for U. S. percentaye loss. Percentage of total listed production in States reporting, 60. 


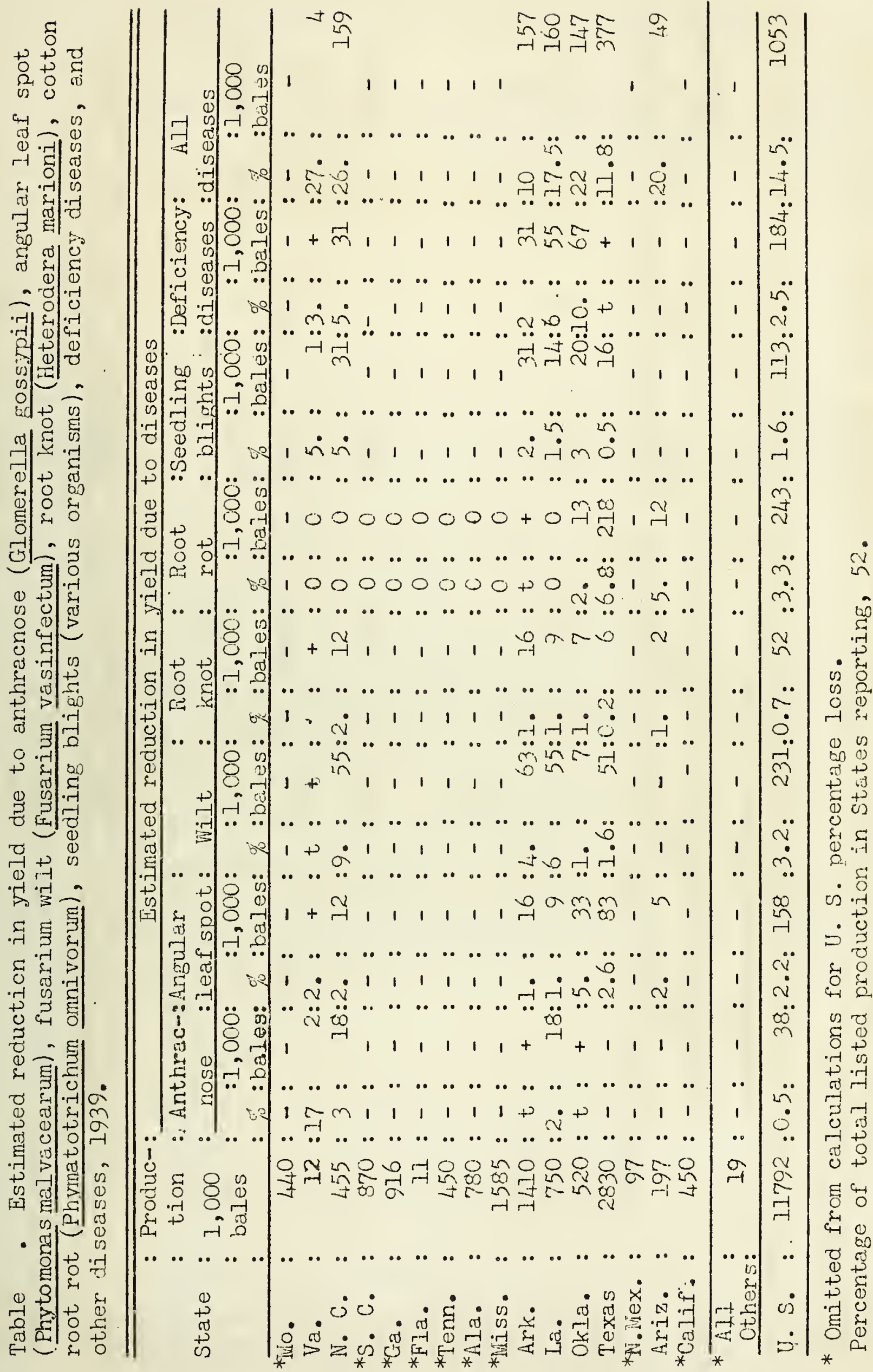




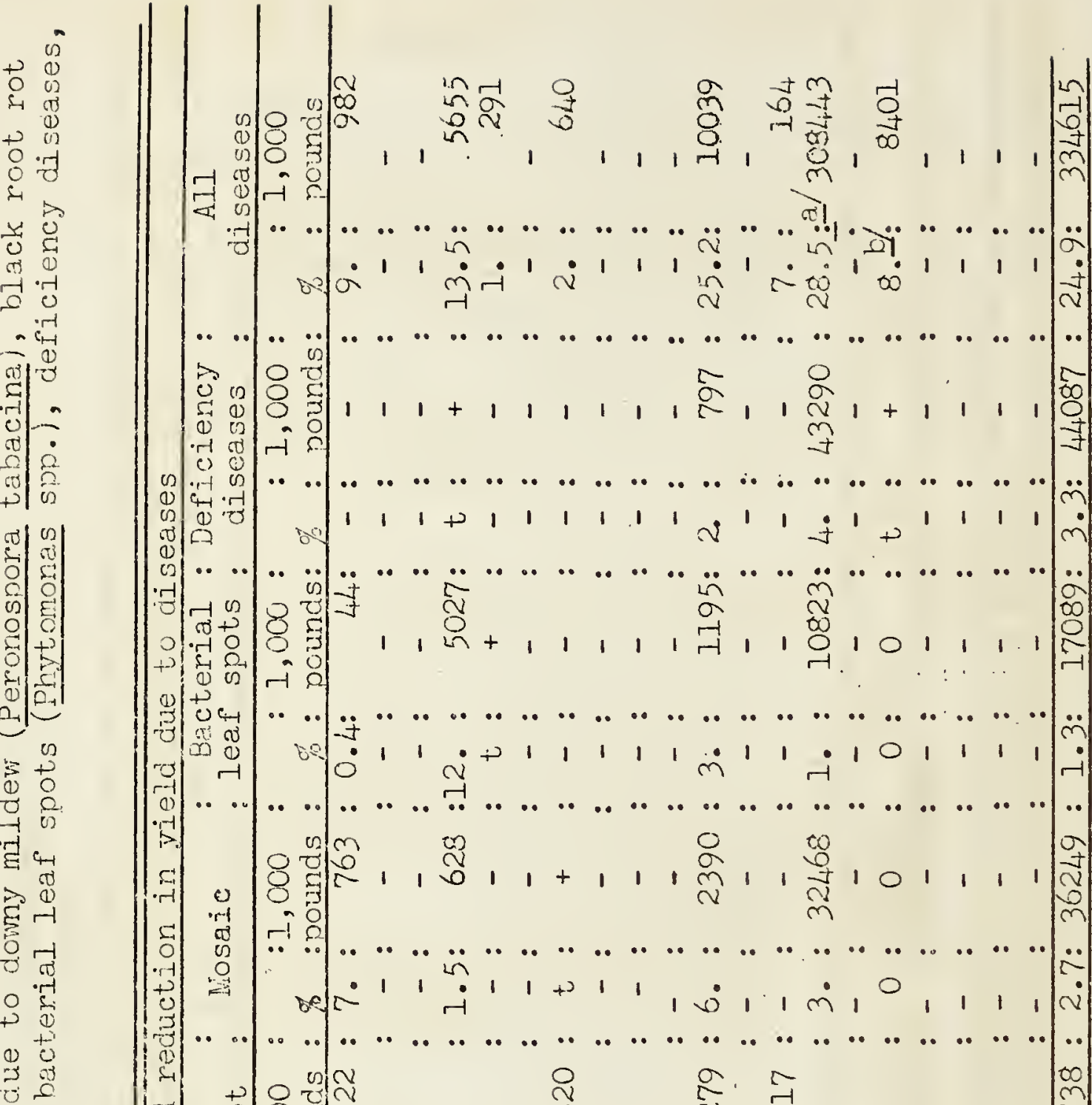

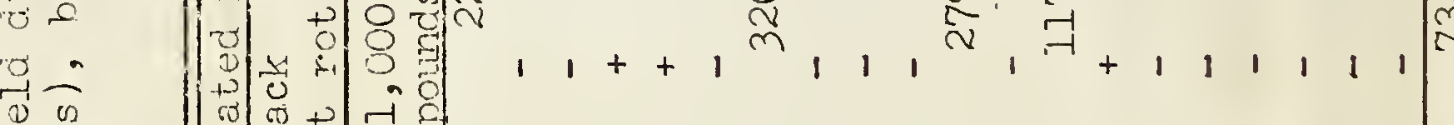

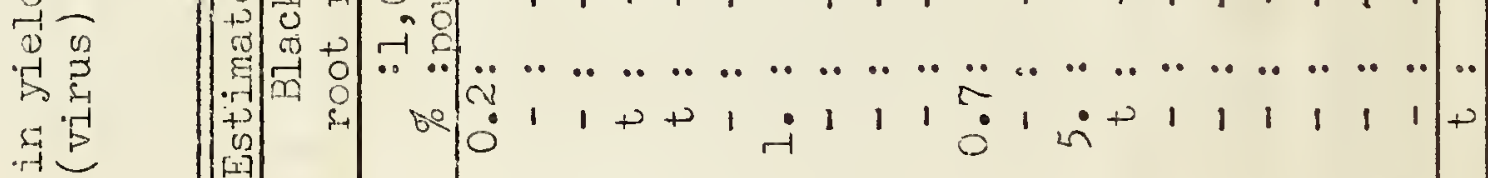

S. 0

$\rightarrow-10$

ยै

(i)

(1)

का का

as 01

然

$\begin{array}{llll}0 & 0\end{array}$

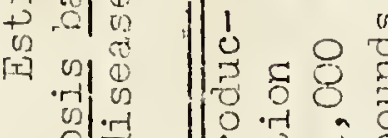

- की

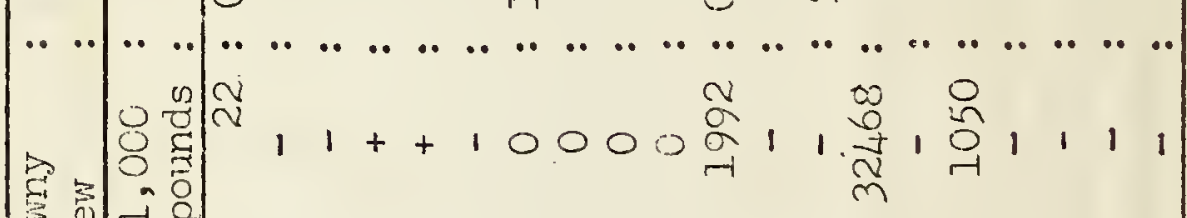

0

己

Of

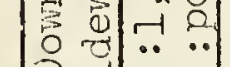

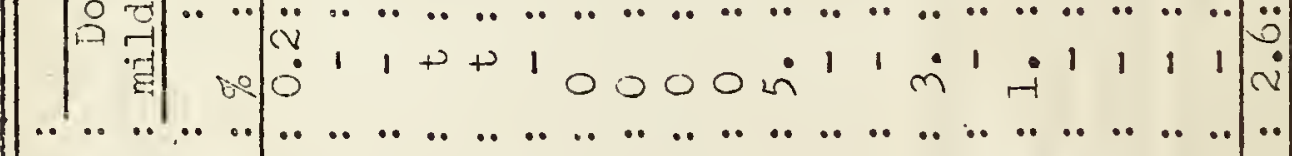

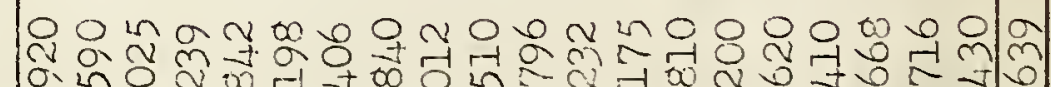

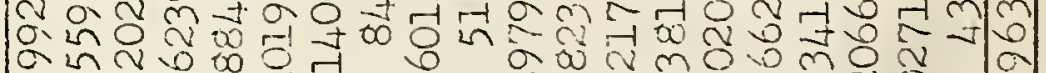
बूे

$$
\|
$$


Table . Estimated reduction in yield due to blight (Erwinia amylovora), scab (Venturia pyrina), leaf blight (Fabraea maculata), and other diseases, 1939.

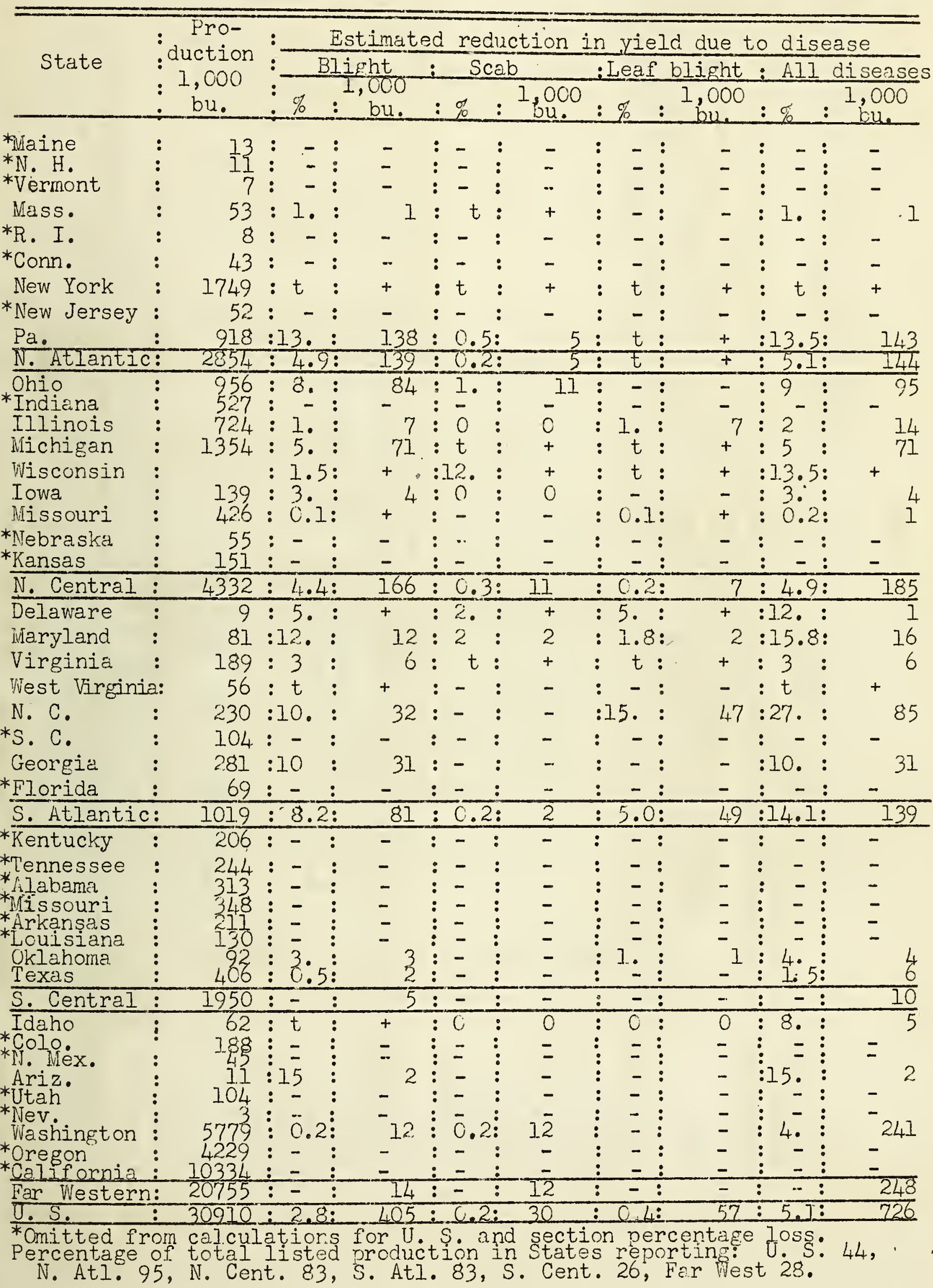




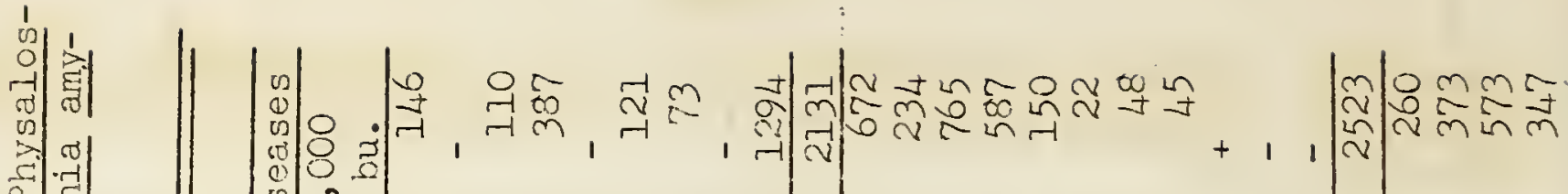
国: 苍点

过

$r-1$

$\therefore 3$

का

苟

武

-1

4

勻

牙嵒命

$+T_{0}^{0}$

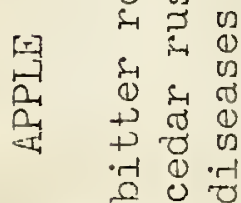

$\circ$.

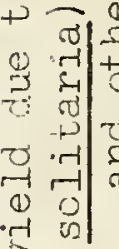

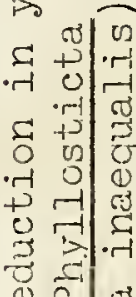

0.010

ه 5 รี

(1)

秀 00

+

n

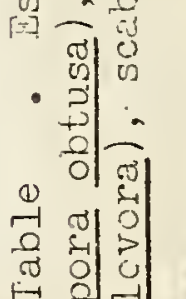

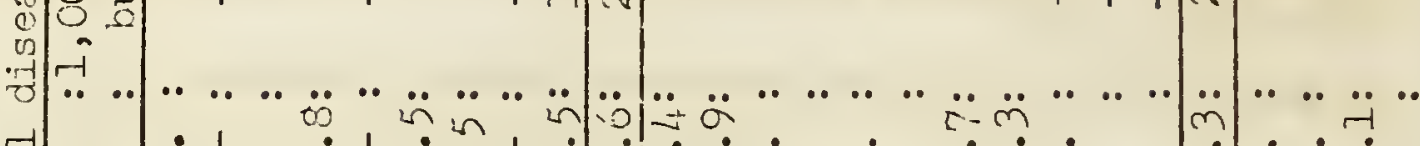
न्द

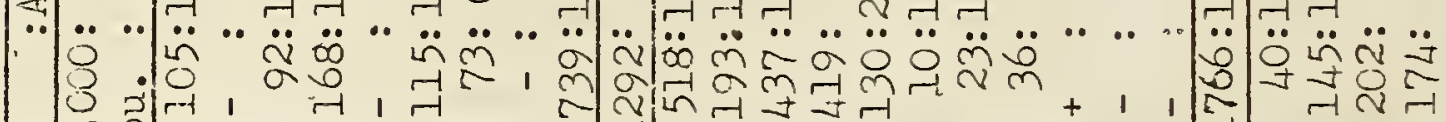

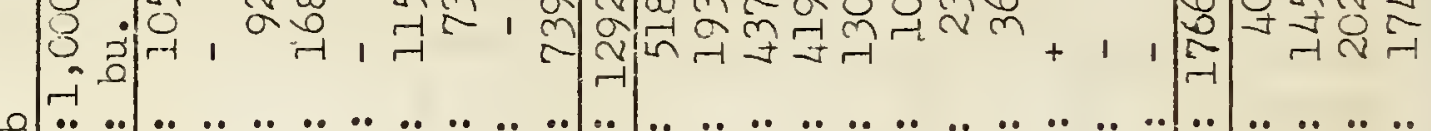

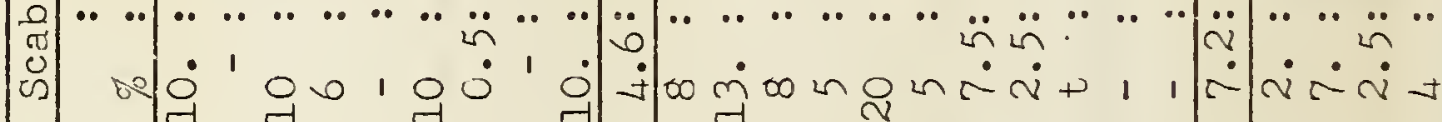

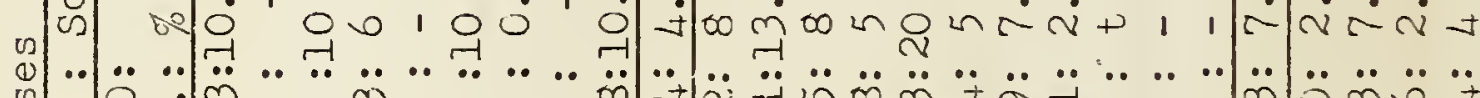

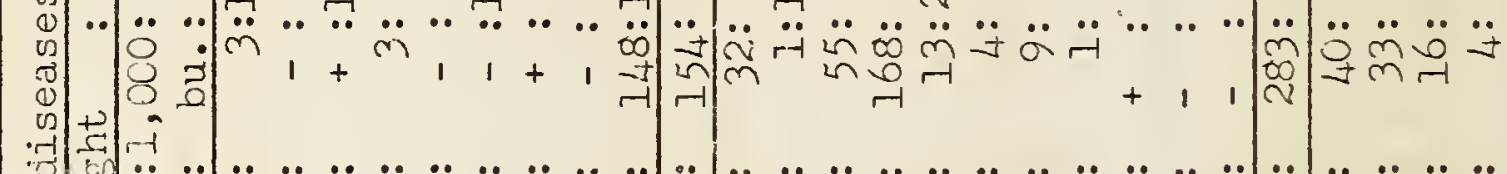

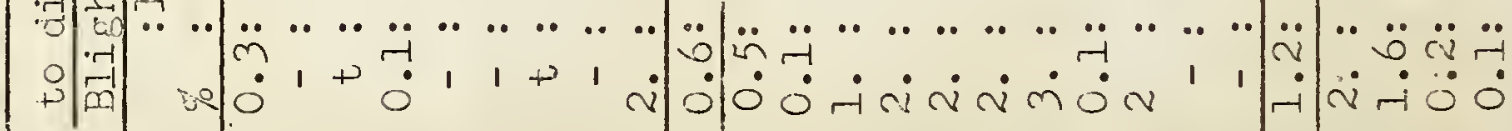

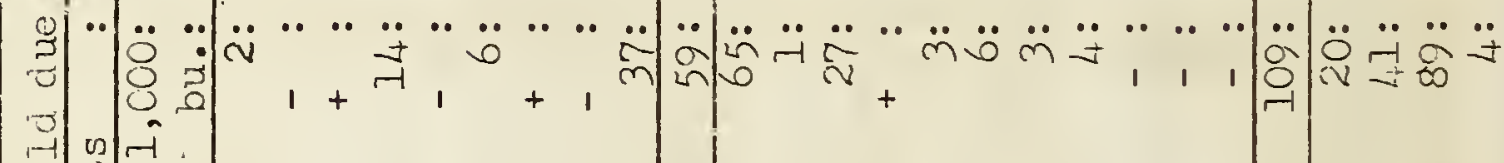

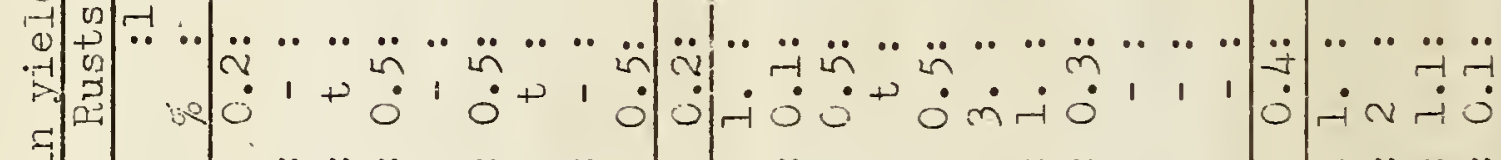

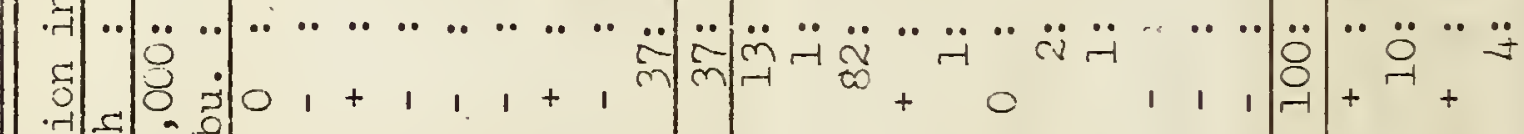

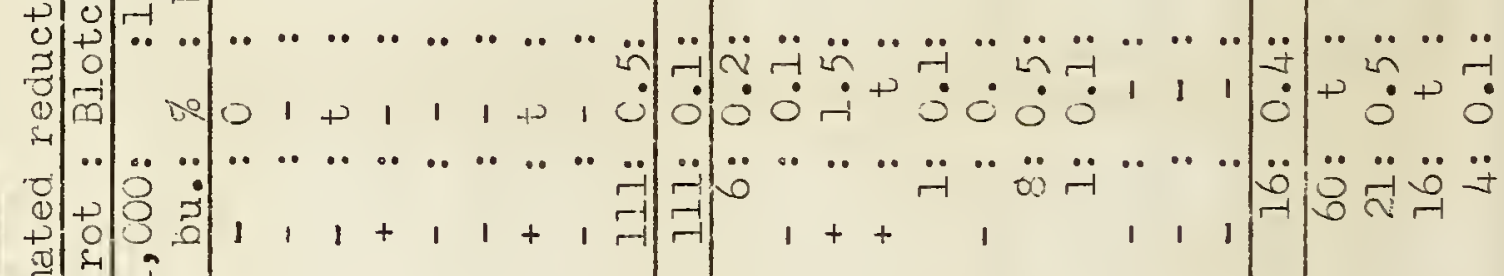

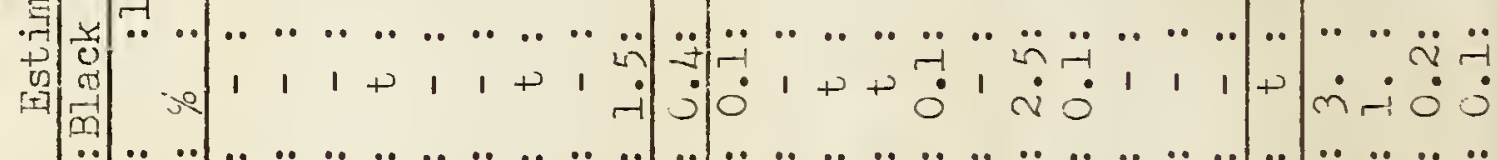

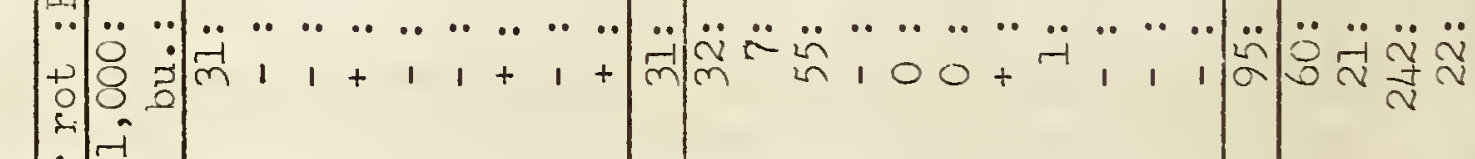

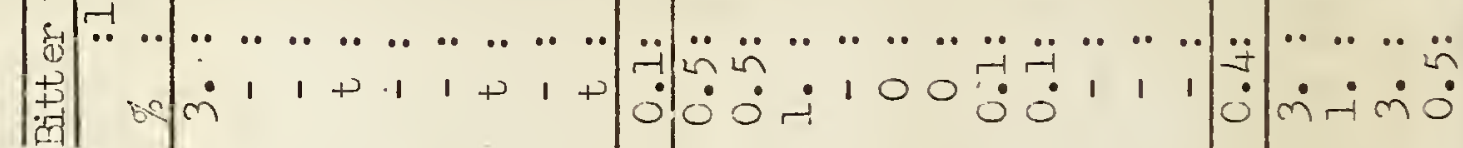

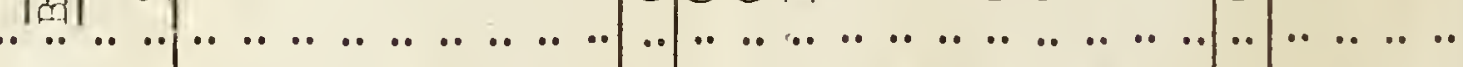

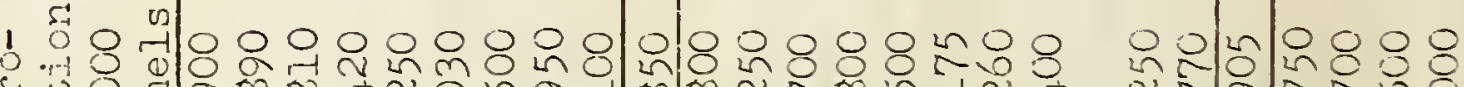

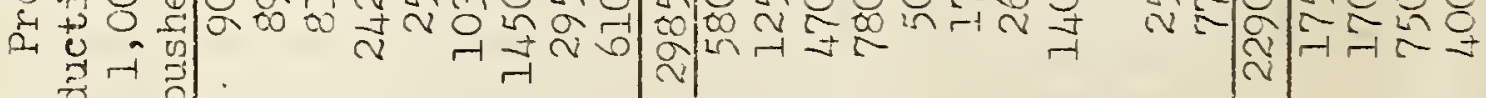

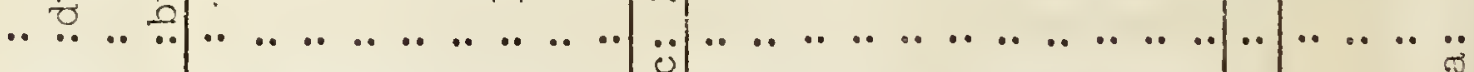

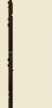

$\underset{+}{4}$

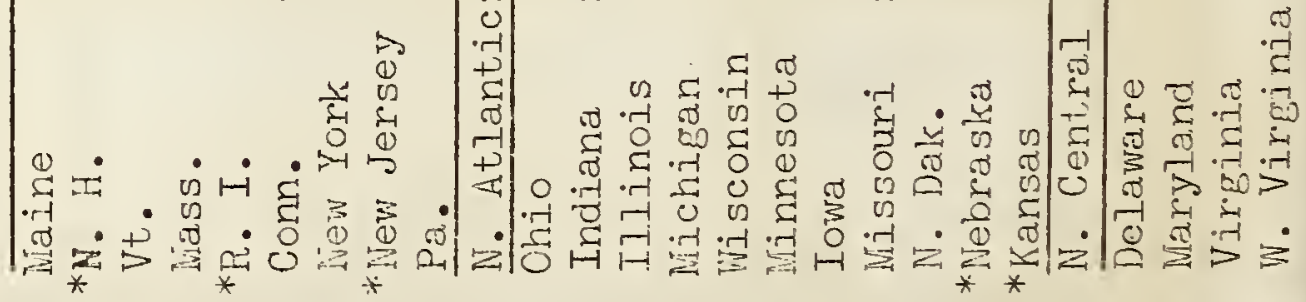




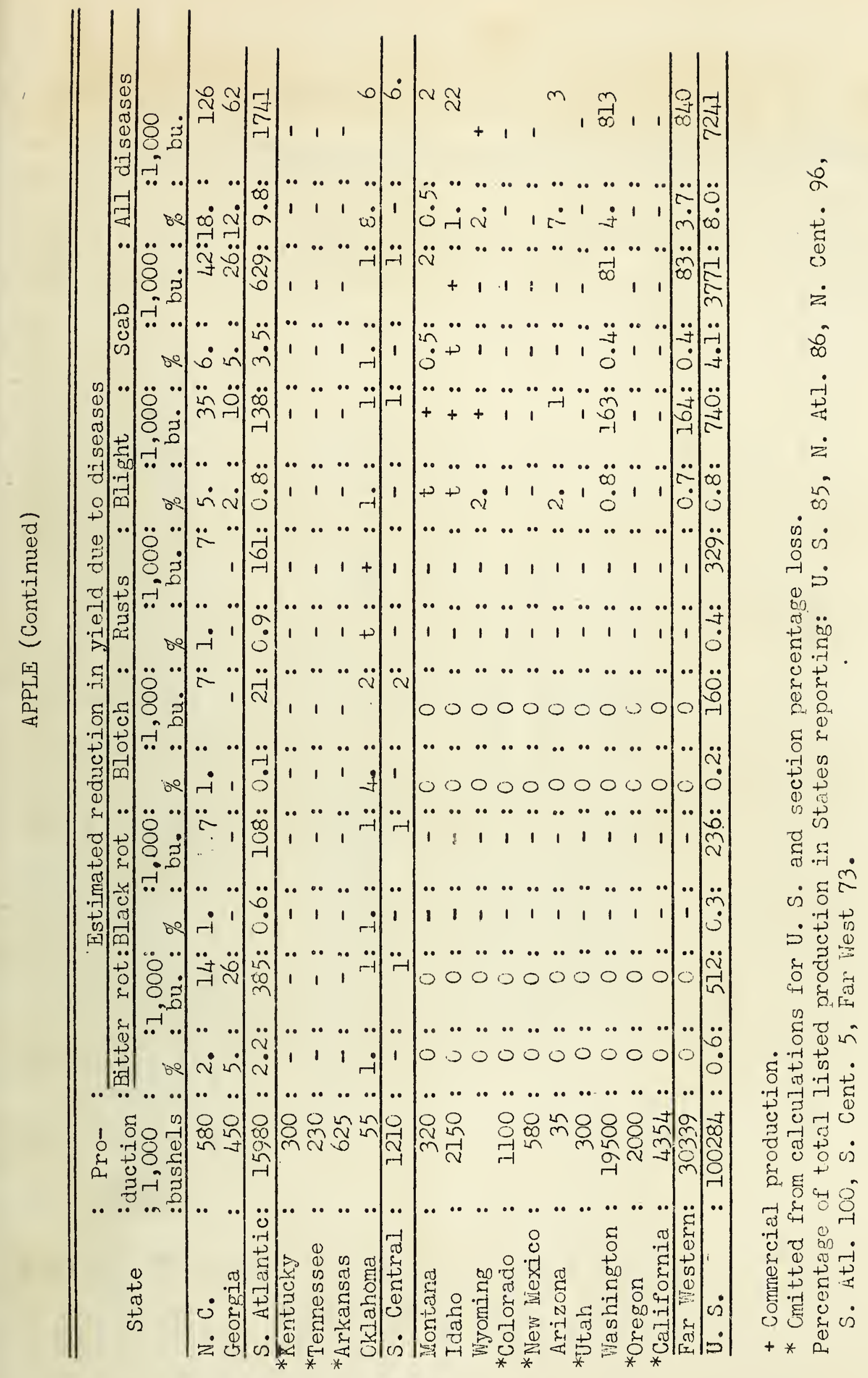


Table - Estimated reduction in yield due to leaf curl (Taphrina deformans), brown rot (Sclerotinia spp.) scab (Cladosporium carpophilum), bacterial spot (Phytomonas pruni) virus diseases and other diseases,1939.

$:$ : $:$ Trotimated reduction in yield due to diseases

State:duction: curl : rot : Scab : spot :diseases: diseases 1,000: :1000: :1000: :1000: :1000: :1000: :1000

$\frac{: \text { bu. }}{27: \%}:$ bu.: $\%:$ bu.: $\%:$ bu.: $\%:$ bu.: $\%:$ bu.: $\%:$ bu.

Nass.: $74: t:+t: 0.5:+: 0.5:+: t:+: 16 .: 14: 17 .: 15$

*R. I.: $12:-$ : - : - : - : - : - : : - : - : - : - :

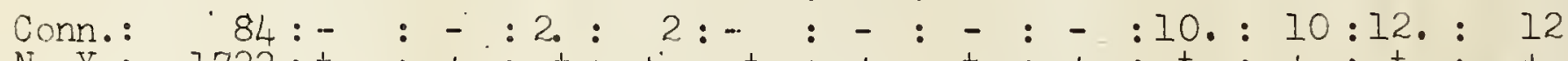

N. Y.: 1722:t $:+: t:+: t:+: t:+: t:+: t: t^{+}$

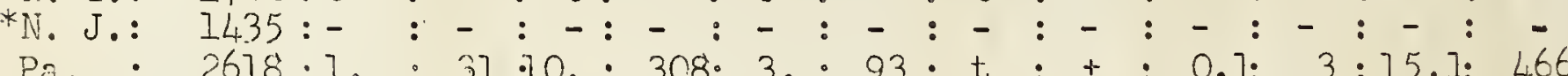

Pa. $: 2618: 1 .: 31: 10 .: 308: 3 .: 93: t: t: 0.1: 3: 15.1: 466$
Onio: $1212: 1 .: 13: 5 .: 66: 2 .: 27: 0.5: 7:-:-: 8: 113$

Ind. : $378: 1 .: 4: 2:$ : $8: 0.1:+:-:-:-:-: 3.1: 12$

Ill. : 2057: t.. + + :3.: 68: 1.: 23: 5.:113: - : - :9.: 204

Mich.: $2760: t:+: 5 .: 147: t:+: t:+: t:+: 6 .: 176$

Iowa : $110: 3 .: 4: 8 .:$ 10:2.: $3: 0.1:+:-:-$ : $13.2: 17$

Mo. : $1140: 0.1: 1: 0.5: 6:-:-:-:-:-:-: 0.6: 7$

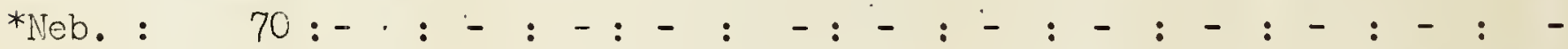

KKan. : $154:-$ : - : - : - : - : - : - : - : - : - : - :

Del. : $422: 5 .: 23: 1 .:$ 5: 1.: $:$ : 1.: $5: t:+: 8 .: 38$

$\mathrm{Ma.}: 427: 3 .: 15: 3.5: 17: 3 .: 15: 1.5: 7: 1 .: 5: 12.2: 60$

$\mathrm{Va},: 990: 1 .: 10: 3.5: 36: t:+: t:+: t:+: 5: 51$

W.Va.: $315: t:+$ : $1 .: 3:-:-:-:-$ : $-:-: 2: 6$

N.C. : $1395: 0.5: 8: 7 .: 113: 2 .: 32: 2 .: 32:-:-\quad: 13.5: 217$

*S.C. : $1484:-$ : - : - : - : - : - : - : - : - : - : - :

Ga.: $4290: 0: 0: 1 .: 52: 1 .: 52: 10 .: 517: 5 .: 258: 17 .: 879$

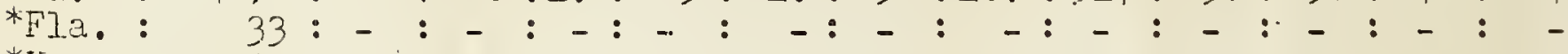

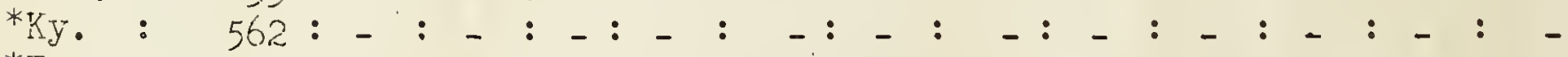

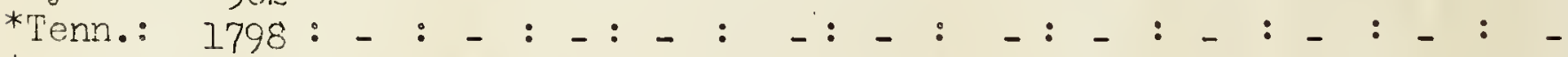

*AI2. : $1705:$ _ : _ : _ _ : _ _ _ : _ _ _ _ : _ : _ : -

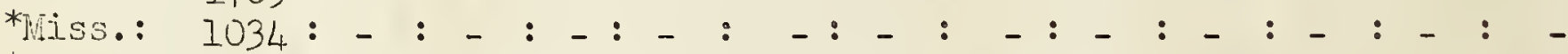

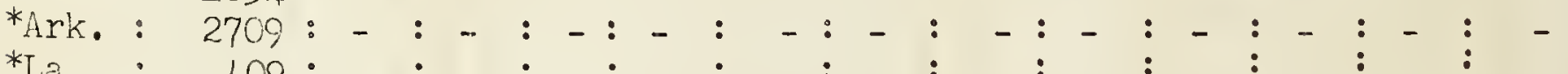

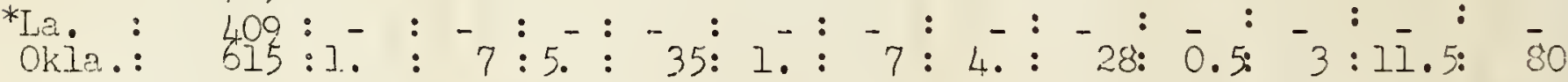

Texas: 1972: $t:+: t:+: 0.5: 10: t:+:-:-: 0.5: 10$

Idaho: $146: t:+: 0 .: 0: 0: 0: 0: 0:-:-: 15.51 / 27$

${ }^{*}$ Colo.: $1575:-$ : - : $-:$ - : - : - : - : - : - : - : - : -

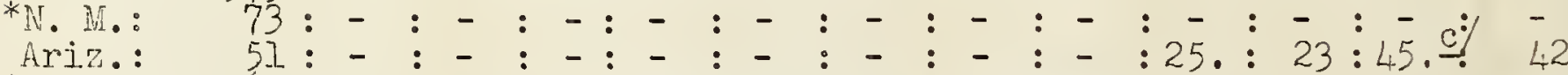

*Utah: $564:-:-:-:-:-:-:-5-: 25 \cdot: 23: 45 \cdot-42$

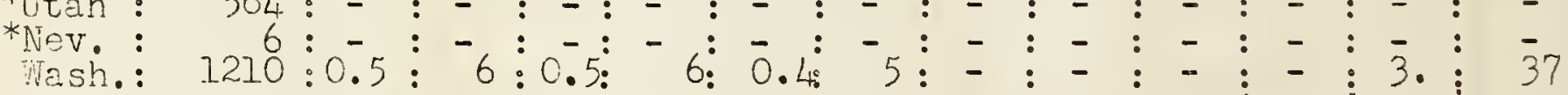

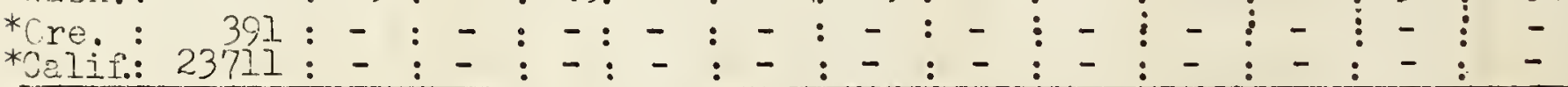

* omited in culculations for U. S. percentage loss.

Percentage of total listed production in states reporting, 39.

e) Brown rot: all s. Pructicola except or the Prcific Coast where both

S. fructicola and $S$. laxa occur.

b/Including chlorosis, Rhizopus rot.

c/ Phymatotrichum 10\%, root knot $10 \%$. 
CHERRY

Table . Estimated reduction in yield due to brown rot (Sclerotinia

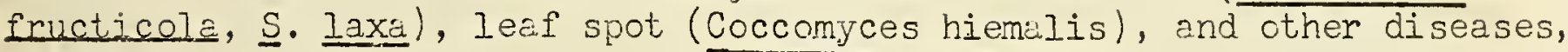
1939.

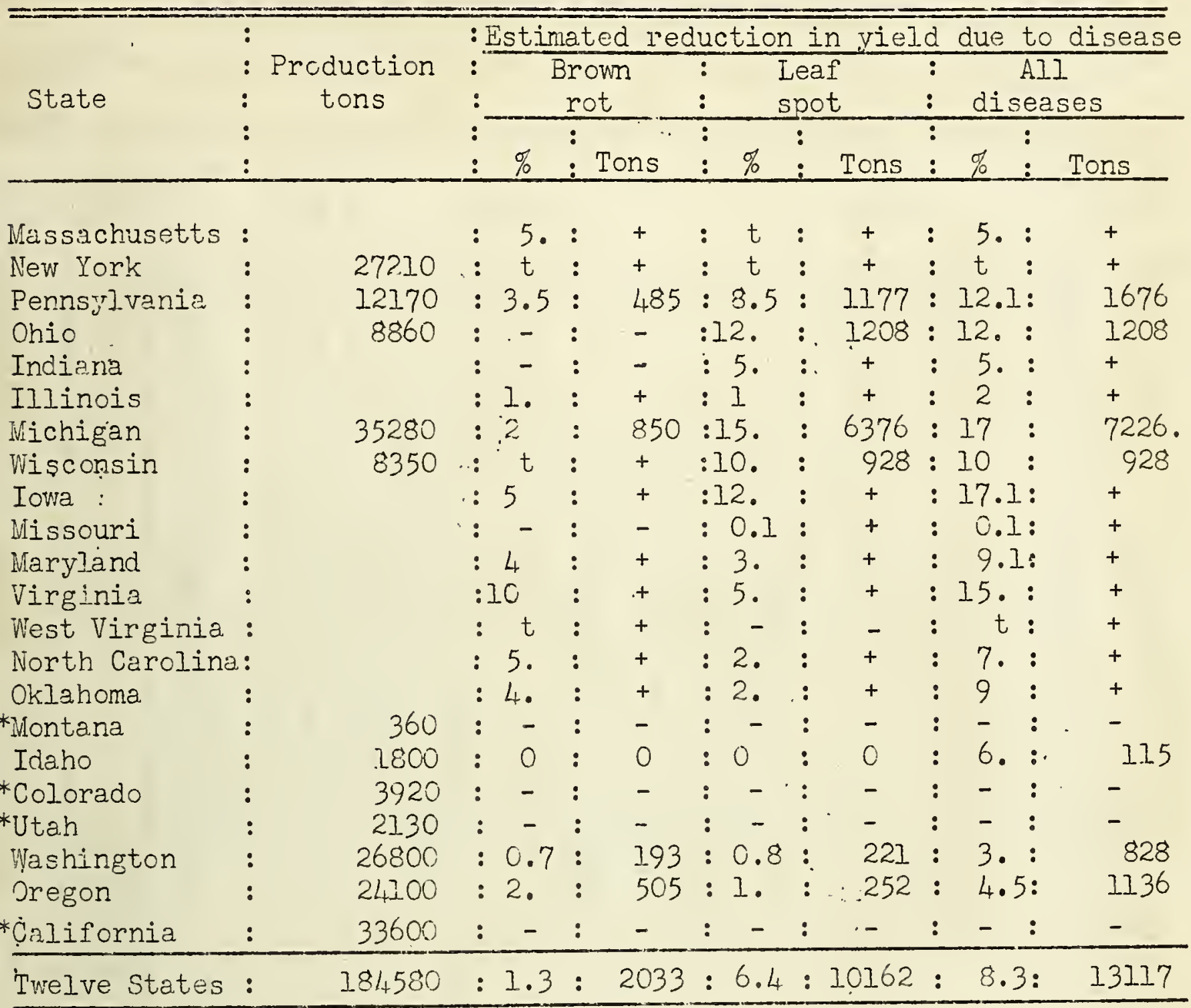

I/ Brown rot, all S. fructicola, except on the Pacific Coast where both species occur. 
STRAWBERRY

Table - Estimated reduction in yield from leaf spot (Mycosphaerella fragariae), leaf scorch (Diplocarpon earliana), root diseases due to various causes, fruit rots" (various organisms), and other di seases, 1939.

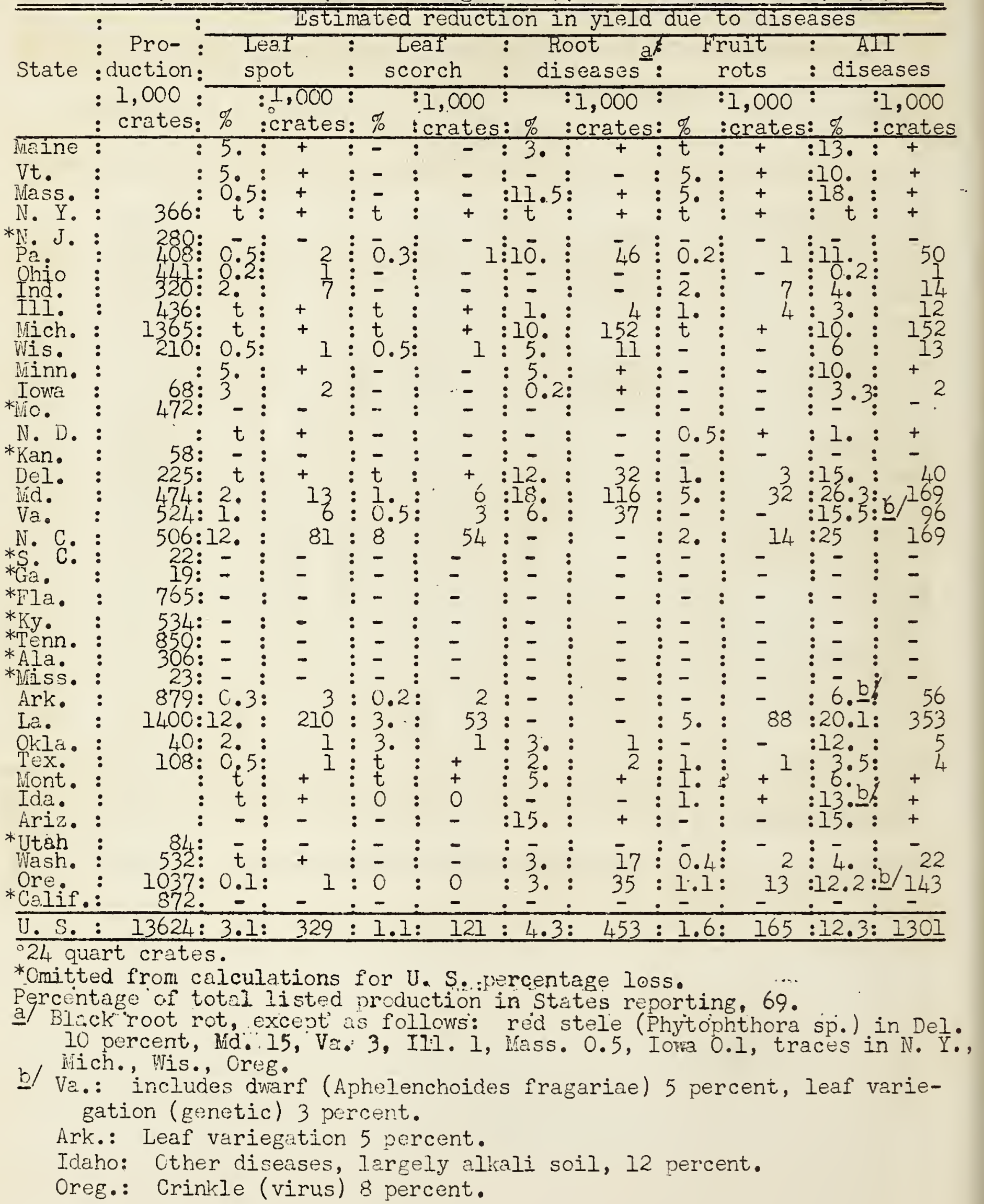


Table - Estimated reduction in yield due to black rot (Guignardia bidwellii), powdery mildew (Uncinula necator), downy mildew (Plasmopara viticola), and other diseases, 1939 .

(1)

State : duction :Black rot :Powdery mildew:Downy mildew:All diseases

\begin{tabular}{|c|c|c|c|c|c|c|c|c|c|c|c|c|}
\hline & & $\%$ & & & & & & $\%$ & ens & & & \\
\hline air & 30 & - & • & : & & & $:$ & - & & & & \\
\hline in & $\begin{array}{r}110 \\
50\end{array}$ & c & $\vdots$ & $\vdots=$ & $\vdots$ & & $\vdots$ & $\overline{-}$ & - & : & c & + \\
\hline & 700 & 2 & 15 & $: t$ & & + & $\vdots$ & 0.5 & & & & \\
\hline & $\begin{array}{l}230 \\
460\end{array}$ & $:-$ & & : & $\vdots$ & - & : & - & - & : & & \\
\hline & $75^{6}+2.0$ & 4. & $\vdots 3150$ & $t$ & : & + & $\vdots$ & $\bar{t}$ & + & & & \\
\hline & & & & & & & : & & 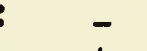 & & & \\
\hline : & : & 9 & $: 2307$ & $: t$ & & + & : & & \pm & & & \\
\hline A & & & 5601 & $:$ & & + & . & l & & 4 & & \\
\hline 14 & 42 & $\vdots 4$ & $: 1793$ & $:=$ & & - & & 0.5 & 2 & & 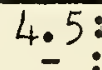 & 20 \\
\hline & : & 1 & : & $\vdots t$ & & + & $\vdots$ & & + & & & \\
\hline WII & : & $: 10$ & : 6456 & : - & • & - & : & & + & & & 4 \\
\hline & : & 3 & 15 & & & & & & 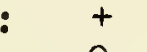 & & & \\
\hline$i r$ & 580 & & $0_{6}$ & & & 0 & $\vdots$ & 0.7 & 0 & & . & \\
\hline$i$ & $\begin{array}{r}1250 \\
300\end{array}$ & -1 & - & $\vdots$ & & - & $\vdots$ & & - & & & \\
\hline ansa & & - & : & $:-$ & & - & $:$ & & & & & \\
\hline
\end{tabular}

N. Central : $140680: 6.7: 8358: t: 6: 0.2: 230: 6.9: 8600$

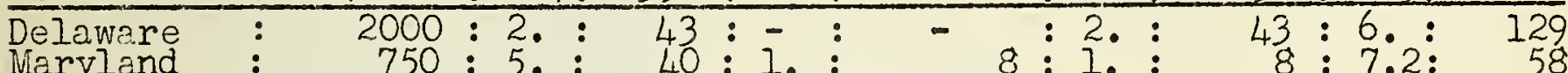

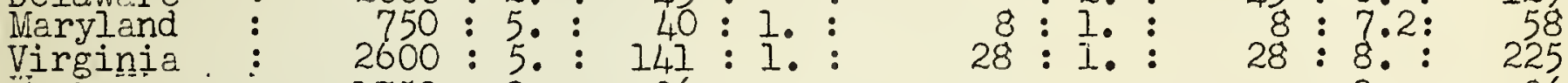

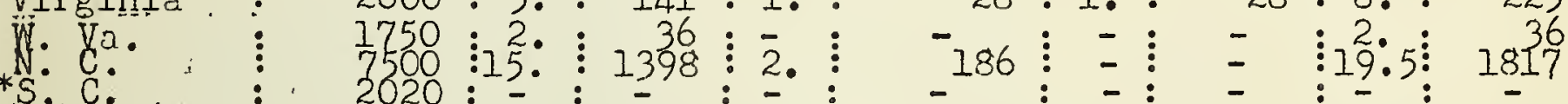

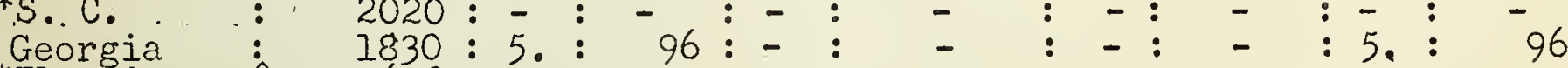

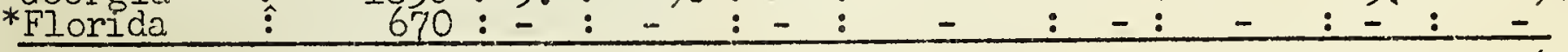

S. Atlantic: $19120: 9.3: 1754: 1.2: \quad 222: 0.4: \quad 79: 12.5: 2361$

$*$ Kentucky

*Tennessee

*Alabama

*Mississippi:

Arkansas

*Louisiana

Oklahoma

Texas

$2750:$

S. Central

Idaho

* Colorado

*New Mexico

Arizona

*Utah

*Nevada

Wash.

Ore.

$2240:-$

$1710:-$

$290:-$

- $:-$

$50:-$

$3200: \overline{7} \cdot \vdots \overline{2} 41:-$

$2800: 1: 28: t:$

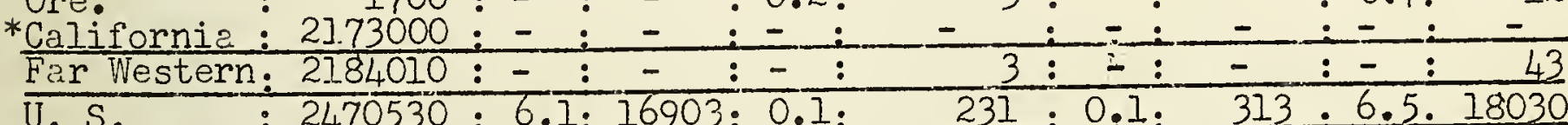

$580: 0: 7: 1190$

$500 \vdots-\vdots-$

$1170:-:-$

$710:-$

$840:-$

$110 \vdots-\vdots$
$5100 \vdots-\vdots$
1700

$\overline{-}$
$\overline{-}$
$\overline{-}$

$-\quad \vdots-\quad \vdots \quad-$

$\overline{-}$

$\overline{1013}$

$+\quad \vdots \overline{1}$

$-\quad \vdots \overline{7} \cdot: \overline{2} 41$

U.S. $: 2470530: 6.1: 16903: 0.1$ :

$+\frac{1}{+}:-:$

$+: 8.3: 1282$

* 0 mitted from calculetions for U. S. and section percentage loss.

Percentage of total listed production in states reporting: for the whole country 10; outside of Far West, 87; N. AtI. 97; N. Cent. 83; S. AtI. 86; S. Cent. 67; Far West 0.4. 
